NASA/TM-2003-212876

\title{
Computational Study of Axisymmetric Off-Design Nozzle Flows
}

Teryn DalBello

University of Toledo, Toledo, Ohio

Nicholas Georgiadis and Dennis Yoder

Glenn Research Center, Cleveland, Ohio

Theo Keith

University of Toledo, Toledo, Ohio 
Since its founding, NASA has been dedicated to the advancement of aeronautics and space science. The NASA Scientific and Technical Information (STI) Program Office plays a key part in helping NASA maintain this important role.

The NASA STI Program Office is operated by Langley Research Center, the Lead Center for NASA's scientific and technical information. The NASA STI Program Office provides access to the NASA STI Database, the largest collection of aeronautical and space science STI in the world. The Program Office is also NASA's institutional mechanism for disseminating the results of its research and development activities. These results are published by NASA in the NASA STI Report Series, which includes the following report types:

- $\quad$ TECHNICAL PUBLICATION. Reports of completed research or a major significant phase of research that present the results of NASA programs and include extensive data or theoretical analysis. Includes compilations of significant scientific and technical data and information deemed to be of continuing reference value. NASA's counterpart of peerreviewed formal professional papers but has less stringent limitations on manuscript length and extent of graphic presentations.

- TECHNICAL MEMORANDUM. Scientific and technical findings that are preliminary or of specialized interest, e.g., quick release reports, working papers, and bibliographies that contain minimal annotation. Does not contain extensive analysis.

- CONTRACTOR REPORT. Scientific and technical findings by NASA-sponsored contractors and grantees.
- CONFERENCE PUBLICATION. Collected papers from scientific and technical conferences, symposia, seminars, or other meetings sponsored or cosponsored by NASA.

- SPECIAL PUBLICATION. Scientific, technical, or historical information from NASA programs, projects, and missions, often concerned with subjects having substantial public interest.

- TECHNICAL TRANSLATION. Englishlanguage translations of foreign scientific and technical material pertinent to NASA's mission.

Specialized services that complement the STI Program Office's diverse offerings include creating custom thesauri, building customized databases, organizing and publishing research results ... even providing videos.

For more information about the NASA STI Program Office, see the following:

- Access the NASA STI Program Home Page at http://www.sti.nasa.gov

- E-mail your question via the Internet to help@sti.nasa.gov

- Fax your question to the NASA Access Help Desk at 301-621-0134

- Telephone the NASA Access Help Desk at 301-621-0390

- Write to:

NASA Access Help Desk

NASA Center for AeroSpace Information 7121 Standard Drive

Hanover, MD 21076 
NASA/TM-2003-212876

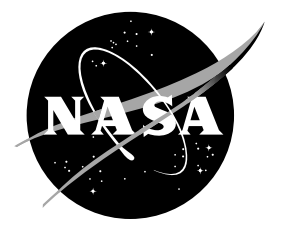

\section{Computational Study of Axisymmetric Off-Design Nozzle Flows}

Teryn DalBello

University of Toledo, Toledo, Ohio

Nicholas Georgiadis and Dennis Yoder

Glenn Research Center, Cleveland, Ohio

Theo Keith

University of Toledo, Toledo, Ohio

Prepared for the

42nd Aerospace Sciences Meeting and Exhibit

sponsored by the American Institute of Aeronautics and Astronautics

Reno, Nevada, January 5-8, 2004

National Aeronautics and

Space Administration

Glenn Research Center 


\section{Acknowledgments}

This work was conducted under grant NCC3-922, sponsored by the Propulsion Research and Technology Project of NASA's Next Generation Launch Technology Program. Help from the following individuals made this work possible: John Slater, John Wolter, Jim DeBonis, and Richey Shyne.

This work was sponsored by the Low Emissions Alternative

Power Project of the Vehicle Systems Program at the NASA Glenn Research Center.

Available from

NASA Center for Aerospace Information 7121 Standard Drive

Hanover, MD 21076
National Technical Information Service 5285 Port Royal Road Springfield, VA 22100 


\title{
COMPUTATIONAL STUDY OF AXISYMMETRIC OFF-DESIGN NOZZLE FLOWS
}

\author{
Teryn DalBello* \\ University of Toledo \\ Toledo, Ohio 43606 \\ Nicholas J. Georgiadis ${ }^{\dagger}$ and Dennis A. Yoder ${ }^{\ddagger}$ \\ National Aeronautics and Space Administration \\ Glenn Research Center \\ Cleveland, Ohio \\ Theo G. Keith ${ }^{\S}$ \\ University of Toledo \\ Toledo, Ohio 43606
}

\begin{abstract}
Computational Fluid Dynamics (CFD) analyses of axisymmetric circular-arc boattail nozzles operating off-design at transonic Mach numbers have been completed. These computations span the very difficult transonic flight regime with shock-induced separations and strong adverse pressure gradients. External afterbody and internal nozzle pressure distributions computed with the Wind code are compared with experimental data. A range of turbulence models were examined, including the Explicit Algebraic Stress model. Computations have been completed at freestream Mach numbers of 0.9 and 1.2, and nozzle pressure ratios (NPR) of 4 and 6. Calculations completed with variable timestepping (steady-state) did not converge to a true steady-state solution. Calculations obtained using constant timestepping (time-accurate) indicate less variations in flow properties compared with steady-state solutions. This failure to converge to a steady-state solution was the result of using variable time-stepping with large-scale separations present in the flow. Nevertheless, time-averaged boattail surface pressure coefficient and internal nozzle pressures show reasonable agreement with experimental data. The SST turbulence model demonstrates the best overall agreement with experimental data.
\end{abstract}

\footnotetext{
* Aerospace Engineer, Member AIAA.

${ }^{\dagger}$ Aerospace Engineer, Nozzle Branch, Associate Fellow AIAA.

‡ Aerospace Engineer, Nozzle Branch, Member AIAA.

$\S$ Distinguished University Professor, Associate Fellow AIAA.
}

\section{INTRODUCTION}

Computational Fluid Dynamics (CFD) analyses of an axisymmetric convergent-divergent boattail nozzle at transonic freestream conditions have been completed to determine the capabilities of Reynolds-Averaged Navier-Stokes (RANS) calculations to predict details of off-design nozzle performance. These studies were performed in support of future high-speed nozzle studies for NASA's Next Generation Launch Technology Program. External and internal nozzle pressure distributions computed with the Wind ${ }^{1}$ code are compared with experimental data obtained in the NASA Langley 16Foot Transonic Tunnel ${ }^{2}$. These computations span the difficult transonic flight regime, in which the flow includes shock-induced separations and strong adverse pressure gradients. At transonic freestream Mach numbers, nozzle boattail drag can significantly affect overall propulsion system performance. Results have been obtained by employing a range of turbulence models available in Wind, including the newly-implemented Explicit Algebraic Reynolds Stress model, in order to assess the capabilities of Wind and its turbulence models to predict these complex flow characteristics. Understanding these effects will aid design for better performance and lower drag in future nozzles.

In this study, computations have been completed at different freestream Mach numbers and nozzle pressure ratios (NPR) on one nozzle configuration, which is represented by the schematic shown in Figure 1. This nozzle, referred to as the "Configuration 2" geometry of Carson and $\mathrm{Lee}^{3}$, is a converging-diverging nozzle. The nozzle operating points considered here are at Mach 0.9 and NPRs of 4 and 6, and Mach 1.2 operating at an 
NPR of 4. Carson and Lee investigated the internal and external pressure distributions on a wide range of nozzles at various Mach numbers and pressure ratios using an interchangeable mechanism on the test rig installed in the Langley 16-Foot Transonic Tunnel. The rig used to obtain experimental results is shown in Figure 2. Carlson ${ }^{4}$ subsequently completed numerical predictions of this work at Mach 0.9 and NPRs of 4, 5, and 6 using the PAB3D CFD code.

\section{NUMERICAL MODEL}

Calculations were obtained with Wind, a general purpose 3-D Computational Fluid Dynamics (CFD) code which solves the turbulent, time-dependent, Reynolds-Averaged Navier-Stokes (RANS) equations using a node-centered finite volume approach. Wind is the production solver of the NPARC Alliance, a joint code development group of NASA Glenn Research Center, USAF Arnold Engineering Development Center, and the Boeing Company. In addition to perfect gas capabilities, Wind can also solve the equations which govern equilibrium air, non-equilibrium air and frozen gas chemistry. Wind version 5 was used for the steady-state calculations and a test version with improved secondorder time-stepping was used for the time-accurate calculations. The solver was configured to run with the following specifications:

- Axisymmetric flow

- Constant timestepping (time-accurate) and variable timestepping (steady-state)

- $\quad$ Second-order Roe upwind scheme with modification for stretched grids, and second-order timemarching

- One-equation Spalart-Allmaras ${ }^{5}$ (S-A), Two-equation Menter Shear Stress Transport ${ }^{6}$ (SST), Chien $\mathrm{k}-\varepsilon^{7}$, and Rumsey-Gatski ${ }^{8,9} \mathrm{k}-\varepsilon$ Explicit Algebraic Reynolds Stress (EASM) turbulence models

- $\quad$ Perfect gas, air, $\gamma=1.4$

The Spalart-Allmaras turbulence model works well for attached and separated wall bounded flows such as the flow around airfoils. The Chien k- $\varepsilon$ model was developed to handle shear layer flows or jet flows. The SST model combines the k- $\omega$ formulation to treat inner regions of wall boundary layers with a transformed k- $\varepsilon$ formulation to handle the outer, mixing regions of the flow. The EASM model has been recently installed in Wind to better predict compressible jet flows. It is derived from a simplified form of the Reynolds Stress transport equation which eliminates the need for the Boussinesq approximation and enables the model to predict anistropy among the Reynolds normal stresses.
However, due to the algebraic nature of the resulting expressions, EASM is not computationally more expensive than linear two-equation models.

The various turbulence models in Wind employ corrections to make them more broadly adaptable to various geometries and conditions. The $\mathrm{k}-\varepsilon$ model has two corrections, namely the Sarkar Compressibility Correction $^{10}$ and the Variable $\mathrm{C}_{\mu}$ correction $^{11}$. The Sarkar approximation, which is designed to improve the prediction of compressible jet flows, is used for all computations shown in this paper. However, results were obtained with the variable $\mathrm{C}_{\mu}$ option both OFF and ON. When activated, this option reduces turbulent viscosity in regions where the production of turbulent kinetic energy is significantly larger than the rate of dissipation. The S-A model was run with and without the streamwise curvature/rotation correction.

The S-A solutions were started from scratch with the TVD factor set to a value of 2, although setting it to a factor of 3 accelerated convergence. SST solutions were started from S-A, and run for an additional 10,000 to 20,000 iterations. The $\mathrm{k}-\varepsilon$ calculations were started from the SST solutions. The EASM was started from a $\mathrm{k}-\varepsilon$ solution. The $d q$ limiter was used to prevent sudden overshoots in all solutions, but the more unsteady models (EASM and $\mathrm{k}-\varepsilon$ ) required it at initialization.

The inflow conditions were specified using the Freestream and Arbitrary Inflow boundary conditions. The Freestream BC is used external to the nozzle and the Arbitrary Inflow is used at the nozzle inflow plane. Total pressure and total temperature were specified and held constant at the inflow boundaries. The static pressure at the outflow boundary was specified to the value of the freestream pressure in subsonic conditions, and supersonic points were extrapolated.

Axisymmetric, structured, computational grids were generated for all cases using Pointwise, Inc's GRIDGEN $^{12}$ software (Figures 3(a), 3(b) and 3(c)). Due to the axisymmetric nature of the problems examined here, images presented in this report are mirrored about the symmetry axis in the figures for clarity. Zonal boundaries were organized in such a way that very complex regions of the flow (such as shear layers) do not run parallel to the zonal boundaries. Average $y+$ values on the viscous walls were specified to be approximately 1 . The convergence criterion consisted of monitoring nozzle thrust for changes with iteration, adequate reduction of the L2 Norm residual, and mass flow conservation within the nozzle.

The computational domain extends radially to about 19 nozzle diameters and extends downstream 
about 50 nozzle diameters. The jet plume zone is 100 points axially and 223 vertically. The inside of the nozzle is 200 axial points by 75 radially, and the freestream around the boattail portion is 200 axially by 60 radially. The forebody is 185 axially by 60 radially. The maximum nozzle outside diameter D is $15.24 \mathrm{~cm}$ and the entire assembly is about $157 \mathrm{~cm}$ (62 inches) long. Significant improvement in the solution (over older, more unrefined grids) was found by adding 91 points axially to the external surface (to get the current 200) and by moving the upper domain boundary more than twice the distance away from the nozzle (to about $142 \mathrm{~cm}$ ). The minimum peak in $\mathrm{Cp}$ on the upper surface was then seen to be predicted more accurately. All results are shown with this improved grid. The downward curvature of the boattail occurs approximately at an x/D of 0 .

A grid dependence study has been conducted on three different grid levels, the coarse being a total of 108,155 points. The medium grid contained $30 \%$ more grid points, and the fine grid contained $60 \%$ more grid points than the coarse grid. Plots of the mean values of pressure coefficient $(\mathrm{Cp})$ over the boattail surface (Figure 4) indicate that the coarse grid is sufficient to capture the pressure distributions. As a result, the coarse grid was used to obtain the results shown in this paper.

Wind was configured to run in multi-processor mode on an SGI Origin 2000. Steady-state solutions took approximately 20 total CPU hours at CFL numbers between 0.6 and 0.8 . Time-accurate solutions took approximately 296 CPU hours at a timestep of 1 nanosecond.

\section{Post Processing}

In order to provide a direct comparison with experimental data, results are represented by $\mathrm{Cp}$ curves on the external surface, and curves of $\mathrm{p} / \mathrm{p}_{\mathrm{t}}$ (static pressure divided by the nozzle total pressure) on the internal surface. In addition, gross thrust is normalized by ideal thrust, and mass flow normalized by ideal mass flow. The pressure coefficient $\mathrm{Cp}$ used in this analysis is defined as the local pressure minus the freestream pressure divided by the freestream dynamic pressure. The gross thrust is obtained through application of the momentum theorem to a control volume surrounding the nozzle:

$$
\begin{aligned}
& \dot{m}_{a}=\sum \rho u \Delta A \\
& F_{a}=\sum\left[\rho u(u)+\left(p-p_{\infty}\right)\right] \Delta A
\end{aligned}
$$

where $u$ is the axial flow velocity component, $\Delta A$ is each cell's computational area, $\rho$ is the density, $p$ is the local static pressure, $F_{a}$ is the actual gross thrust extracted from the Wind solution, and $m_{a}$ is the actual mass flow extracted from the Wind solution.

Ideal mass-flow rate and thrust are determined from the isentropic flow equations and are used to normalize the calculated thrust and mass flow:

$$
\begin{aligned}
& \dot{m}_{i}=P_{t} A_{\text {throat }} \sqrt{\frac{\gamma}{R T_{t}}\left(\frac{2}{\gamma+1}\right)^{\frac{\gamma+1}{\gamma-1}}} \\
& \left.F_{i}=\dot{m}_{a} \sqrt{\frac{2 \gamma}{\gamma-1} R T_{t}\left[1-\left(\frac{p_{\infty}}{p_{t}}\right)^{\frac{\gamma-1}{\gamma}}\right]}\right]
\end{aligned}
$$

where $\mathrm{p}_{\mathrm{t}}$ and $\mathrm{T}_{\mathrm{t}}$ are the nozzle total pressure and temperature, respectively, and $\gamma$ is the ratio of the specific heats.

During the course of the computations, variations in inflow properties were seen in the steady-state calculations requiring subsequent analysis using time-accurate calculations to determine the significance of the variations. As a result, variations in flow properties of the steady-state and time-accurate solutions across time (or iterations) are represented by the Standard Deviation (SD). The SD gives an indication of where across the surface and to what degree a variation of a particular flow quantity occurs. The mean values and SD of a flow quantity are given by:

$$
\begin{gathered}
\text { mean }=\overline{\operatorname{var}}(x)=\frac{\sum_{n=1}^{N} \operatorname{var}(x, n)}{N} \\
S D=\sigma_{\operatorname{var}(x)}=\frac{\sum_{n=1}^{N}(\operatorname{var}(x, n)-\overline{\operatorname{var}}(x))^{2}}{N-1}
\end{gathered}
$$

where $N$ is the number of solution files to average, $x$ is a point of interest on the surface, and var represents the flow quantity or variable of interest (either $\mathrm{Cp}$ or $\mathrm{p} / \mathrm{p}_{\mathrm{t}}$ in this analysis).

\section{DESCRIPTION OF CASES AND RESULTS}

Results are presented as pressure distributions on the internal and external nozzle surfaces and Mach number contours of the entire flowfield. The pressure distributions are compared to experimental data for several NPRs and freestream Mach numbers. Designed to oper- 
ate at an NPR of 21.23, the "Configuration 2" nozzle was run at off-design NPRs of 4 and 6 . The relatively shallow downward slope (3.8 degrees) of the external surface results in attached flow across the entire upper surface. The inner nozzle is wedge shaped (linear wall contour) with a half angle of 13.18 degrees. This results in separation on the inner surface for all NPRs below 6 . The separation location moves forward (towards the nozzle throat) as the NPR is lowered.

An on-design solution (NPR=21.23) for the "Configuration 2" nozzle is shown in Figure 5 and serves as a reference, and will not be discussed in detail. In all cases, the forebody structure used in the experiment is modeled in the CFD computations, which influences the external nozzle boattail by adding upstream effects, primarily well-developed boundary layers.

Generally, all solutions showed flow accelerating supersonically through the nozzle, followed by the formation of a sophisticated array of shocks and expansion waves. More significantly, as a result of the nozzles operating at lower-than-design NPRs, this complex set of expansion and shock waves resulted in large-scale flow separation and unsteadiness near the nozzle exit, also affecting the pressure distribution on the top surface. The pressure values for both the steady-state and time-accurate solutions on the internal and external surfaces were time- or iteration-averaged across several thousand iterations to obtain the mean values. These values are compared to experimental data.

The three cases are examined in more detail below. These consist of results at Mach 0.9 and NPRs of 4 and 6, and Mach 1.2 operating at an NPR of 4 . In addition to the steady-state calculations using all turbulence models common to all three cases, the Mach 0.9, NPR 4 case consists of an additional time-accurate calculation using the SST model.

\section{MACH 0.9, NPR 4}

The flow conditions can be seen in Table 1. First, the steady-state solution will be discussed, followed by discussion of a time-accurate computation using the SST turbulence model.

Table 1: Nozzle flow conditions

\begin{tabular}{|l|c|c|}
\hline & Freestream & Nozzle Inflow \\
\hline \hline Mach No. & 0.9 & 0.2 \\
\hline Total Temp & $579.6 \mathrm{R}$ & $540.0 \mathrm{R}$ \\
\hline Total Pressure & $14.7 \mathrm{psi}$ & $34.77 \mathrm{psi}$ \\
\hline
\end{tabular}

Table 1: Nozzle flow conditions

\begin{tabular}{|c|c|c|}
\hline & Freestream & Nozzle Inflow \\
\hline \hline Static Pressure & $8.69 \mathrm{psi}$ & $32.43 \mathrm{psi}$ \\
\hline
\end{tabular}

\section{STEADY-STATE CALCULATIONS}

Figure 6(a) shows a qualitative view of Mach number contours at the off-design $\mathrm{NPR}=4$, Mach 0.9 around the entire body, while Figure 6(b) shows details near the nozzle exit. Figure 7(a) shows the mean Cp profiles on the upper surface. Figure 7(b) shows the analogous curves for the internal surface, plotted using $\mathrm{p} / \mathrm{p}_{\mathrm{t}}$. In Figure 7(a), the k- $\varepsilon$ solution with $\mathrm{C}_{\mu}$ ON shows the closest agreement to minimum peak on the upper surface near $\mathrm{x} / \mathrm{D}=0.0$, while it overpredicts the pressure near $\mathrm{x} / \mathrm{D}=1.0$, compared with the S-A and SST models. Turning the $\mathrm{C}_{\mu}$ option OFF slightly improved the pressure distributions over having it $\mathrm{ON}$ (near $\mathrm{x} / \mathrm{D}$ of 1.0). The sudden jump in pressure around $\mathrm{x} / \mathrm{D}$ of 0.7 , as seen in Figure 7(b), results from flow passing through the shock that contacts the nozzle wall (Figure 6(b)). Solutions exhibiting more forward shock locations ( e.g., for the EASM, $\mathrm{k}-\varepsilon$ models) result in higher pressure at the exit, creating a higher adverse pressure gradient field for the top surface, causing separation to move upstream, as indicated in Figure 7(a) by the higher $\mathrm{Cp}$ values at $\mathrm{x} / \mathrm{D}$ of 1.0 .

This case exhibited the most apparent unsteadiness, which results from a shock-induced separation on the inner nozzle surface at an x/D of about 0.7 . For NPR values lower than 6 , the internal surface separates, and this separation region interacting with the shock causes a low-frequency unsteady behavior on the top of the boattail surface itself, causing the pressure to oscillate. The external pressure distribution (Figure 7(a)) experences a fair amount of unsteadiness as indicated by the SD plot on the external surface shown in Figure 8(a). The EASM model generates the highest values of SD. This apparent unsteadiness is related to the shockwave/ boundary layer interaction and the resultant magnitude of the separation. The k- $\varepsilon$ and EASM solutions showed the highest peaks in SD indicating the most variation in flow properties. The SST and SA models are better able to calculate the separation region.

Figure 8(a) shows that turning the $\mathrm{C}_{\mu}$ option OFF reduced the apparent unsteadiness considerably (low values of SD). When the $\mathrm{C}_{\mu}$ option is $\mathrm{ON}$, the turbulent viscosity is indirectly reduced or limited in those regions, and has less damping effect on the apparent unsteadiness. The internal surface pressure (Figure 7(b)) also exhibits variation in pressure due to unsteadi- 
ness as seen in Figure 8(b). The spikes in unsteadiness occur around the location where the shock contacts the wall, a possible source of the pulsing driving the unsteadiness on the upper surface. As on the top surface, turning the $\mathrm{C}_{\mu}$ option OFF with $\mathrm{k}-\varepsilon$ reduced the unsteadiness, possibly by not limiting the amount of turbulent viscosity in that region.

Figure 9 shows the instantaneous streamlines for each turbulence model that bound the separation region just inside the nozzle exit. The S-A solution with streamwise curvature correction $O N$ showed the least separation off the inner surface, while the EASM model predicted the most separation. The relative positions of streamlines seen in Figure 9 is probably related to the

Table 2: Comparison of normalized massflow and thrust for various turbulence models. "cc" refers to the $S-A$ rotation correction.

\begin{tabular}{|c|c|c|}
\hline $\begin{array}{c}\text { Mach 0.9, } \\
\text { NPR 4 }\end{array}$ & $\begin{array}{c}\text { Normalized } \\
\text { Thrust }\end{array}$ & $\begin{array}{c}\text { Normalized } \\
\text { Massflow }\end{array}$ \\
\hline \hline Experiment & 0.8063 & 0.9700 \\
\hline S-A (cc OFF) & 0.7810 & 0.9584 \\
\hline S-A (cc ON) & 0.7717 & 0.9550 \\
\hline SST & 0.8019 & 0.9622 \\
\hline EASM & 0.8587 & 0.9740 \\
\hline $\mathrm{k}-\varepsilon\left(\mathrm{C}_{\mu}\right.$ OFF) & 0.8456 & 0.9721 \\
\hline $\mathrm{k}-\varepsilon\left(\mathrm{C}_{\mu}\right.$ ON) & 0.8569 & 0.9714 \\
\hline
\end{tabular}

relative magnitudes of $\mathrm{Cp}$ values found near $\mathrm{x} / \mathrm{D}$ of 1.0 in Figure 7(a). Table 2 shows the normalized thrust and massflows for each turbulence model versus experimental data. Actual thrust and massflow are normalized by the ideal quantities. The thrust values for the $\mathrm{k}-\varepsilon$ and EASM models are higher than indicated by experiment while the S-A models are lower, and SST provides the best overall prediction.

\section{Time-ACCURATe Calculations}

Because the variable-timestep (steady-state) solutions indicated significant variation in flow properties (failure to converge to a steady-state solution) internal and external to the nozzle, an additional time-accurate calculation using the SST model was completed for this case to investigate these effects. The time-accurate solution was restarted from the "steady-state" solution, and run for 458,000 iterations at a timestep of 1 nano- second $\left(10^{-9}\right)$. A "characteristic time" $t_{c}$ for a fluid particle to move one nozzle diameter can be defined as:

$$
t_{c}=\frac{D_{\text {exit }}}{u_{\text {exit }}}
$$

where $D_{\text {exit }}$ is the exit diameter of $13.2 \mathrm{~cm}(0.433 \mathrm{ft})$ and $u_{\text {exit }}$ is $2,000 \mathrm{ft} / \mathrm{sec}$. The total time $\Delta \mathrm{T}$ passed over $\mathrm{N}$ iterations is:

$$
\Delta T=N \Delta t
$$

where $\Delta \mathrm{t}$ is $10^{-9}$ seconds. From this, one can see that at 458,000 iterations, a fluid particle has moved 2.11 nozzle diameters downstream.

Figures 10(a) and 10(b) show the mean pressure distributions external and internal to the nozzle for the steady-state solution, experimental values and timeaccurate solution. The mean values from the time-accurate solutions are very close to the steady-state solutions, as seen in these figures. Additionally, the SD plots (Figures 11(a) and 11(b)) indicate that the variation of pressure is small compared to what was observed in the steady-state Standard Deviation plots (Figures 8(a) and 8(b)). In Figure 10(a), the time-accurate solution predicts a slightly higher value of $\mathrm{Cp}$ near $\mathrm{x} / \mathrm{D}$ of 0.5 compared with the steady-state solution. Figure 10(b) indicates that the time-averaged steady-state solution on the internal surface is the same as that of the time-accurate solution. Furthermore, Figure 9 demonstrates that even the instantaneous streamlines for the the steady-state and time-accurate solutions give almost identical results. The time-accurate numerics appear to remove the numerical instabilities associated with the unsteady separation and enable a nearly converged solution to be obtained. In light of this, the time-accurate solutions suggest that the non-realistic variation in pressure seen in the steady-state calculations is partially the result of using a variable timestep (constant CFL number). Similar phenomenon have been observed in calculations with separated flow on multi-element airfoil calculations at high lift ${ }^{13}$, and in calculations of a lobed nozzle with a large separated base region ${ }^{14}$.

\section{MACH 0.9, NPR 6}

The flow conditions for this case are listed in Table 3. The Mach number contours are shown in Figure 12, and indicate less dramatic formation of expansion and shock waves near the nozzle exit. The normal shock has moved beyond the nozzle exit, and has decreased in its severity. A much smaller region of separated flow on the inner wall is present near an $\mathrm{x} / \mathrm{D}$ of 0.95 compared with the Mach 0.9, NPR 4 case. Pressure distributions 
Table 3: Nozzle flow conditions

\begin{tabular}{|l|c|c|}
\hline & Freestream & Nozzle Inflow \\
\hline \hline Mach No. & 0.9 & 0.2 \\
\hline Total Temp & $579.6 \mathrm{R}$ & $540.0 \mathrm{R}$ \\
\hline Total Pressure & $14.7 \mathrm{psi}$ & $52.15 \mathrm{psi}$ \\
\hline Static Pressure & $8.69 \mathrm{psi}$ & $50.74 \mathrm{psi}$ \\
\hline
\end{tabular}

for the internal and external surfaces are shown in Figures 13(a) and 13(b). All turbulence models slightly underpredict the pressure distribution on the internal surface at an $x / D$ of 0.15 as seen in Figure 13(b). The k$\varepsilon$ and EASM models predicted the separation point earlier than the other models as seen in Figure 13(b). Again, the SST model predicts the pressure distribution the best across both the internal and external surfaces. Figures 14(a) and 14(b) show the SD for the external and internal surfaces, respectively. The S-A model shows the highest variations in SD compared with the NPR 4 case on the external surface (Figure 14(a) vs Figure 8(a)), and EASM the lowest. The internal surface SD plot, Figure 14(b), showed similar trends between the NPRs 4 and 6 cases, with the k- $\varepsilon$ model having the highest values, and S-A the lowest. The variable $\mathrm{C}_{\mu}$ option did not seem to affect the damping of the unsteadiness for this case. Table 4 shows normalized mass flow and thrust for each turbulence model compared with experimental data. The SST and SA solutions provide the best agreement with the experimental thrust values. All turbulence models gave very similar mass flow values and fall slightly below the experimental values.

Table 4: Comparison of normalized massflow and thrust for various turbulence models. "cc" refers to the $S-A$ rotation correction.

\begin{tabular}{|c|c|c|}
\hline $\begin{array}{c}\text { Mach 0.9, } \\
\text { NPR 6 }\end{array}$ & $\begin{array}{c}\text { Normalized } \\
\text { Thrust }\end{array}$ & $\begin{array}{c}\text { Normalized } \\
\text { Massflow }\end{array}$ \\
\hline \hline Experiment & 0.8625 & 0.9680 \\
\hline S-A (cc OFF) & 0.8615 & 0.9523 \\
\hline S-A (cc ON) & 0.8603 & 0.9525 \\
\hline SST & 0.8639 & 0.9524 \\
\hline EASM & 0.8898 & 0.9551 \\
\hline
\end{tabular}

Table 4: Comparison of normalized massflow and thrust for various turbulence models. "cc" refers to the $\mathrm{S}-\mathrm{A}$ rotation correction.

\begin{tabular}{|c|c|c|}
\hline $\begin{array}{c}\text { Mach 0.9, } \\
\text { NPR 6 }\end{array}$ & $\begin{array}{c}\text { Normalized } \\
\text { Thrust }\end{array}$ & $\begin{array}{c}\text { Normalized } \\
\text { Massflow }\end{array}$ \\
\hline \hline $\mathrm{k}-\varepsilon\left(\mathrm{C}_{\mu}\right.$ OFF $)$ & 0.8858 & 0.9546 \\
\hline $\mathrm{k}-\varepsilon\left(\mathrm{C}_{\mu} \mathrm{ON}\right)$ & 0.8894 & 0.9534 \\
\hline
\end{tabular}

\section{MACH 1.2, NPR 4}

The results for this case resulted in a significant change in the appearance of the internal and external flowfield (in terms of Mach number contours and pressure contours) compared to the subsonic case at the same NPR. The flow conditions are listed in Table 5. The Mach number contours are shown in Figure 15 and

Table 5: Nozzle flow conditions

\begin{tabular}{|l|c|c|}
\hline & Freestream & Nozzle Inflow \\
\hline \hline Mach No. & 1.2 & 0.2 \\
\hline Total Temp & $579.6 \mathrm{R}$ & $540.0 \mathrm{R}$ \\
\hline Total Pressure & $14.7 \mathrm{psi}$ & $24.25 \mathrm{psi}$ \\
\hline Static Pressure & $6.062 \mathrm{psi}$ & $23.59 \mathrm{psi}$ \\
\hline
\end{tabular}

indicate less dramatic formation of expansion and shockwaves near the exit compared to the Mach 0.9 cases. The normal shock structure and severity is similar to the Mach 0.9, NPR 6 case. This suggests that increasing the freestream speed has the equivalent effect of increasing the nozzle pressure ratio (through the effect of flow entrainment). The separated flow region on the inner nozzle wall is very small. Figures 16(a) and 16(b) show the pressure distributions on the external and internal surfaces respectively. All turbulence models slightly underpredict the pressure at an $\mathrm{x} / \mathrm{D}$ of 0.15 as seen in Figure 16(b) (more so than in the Mach 0.9, NPR 6 case). Similar to the subsonic cases, the k- $\varepsilon$ model predicts an early separation region, but the EASM model predicts its location slightly better than in the subsonic cases. The predicted pressures along the external surface (from $\mathrm{x} / \mathrm{D}$ of 0.125 to 0.9 ) were overpredicted slightly by all turbulence models as seen in Figure 16(a). The EASM model predicts the pressure distribution well towards $\mathrm{x} / \mathrm{D}$ of 1.0 (nozzle exit); but the SST model provides the best overall prediction of both. Figures 17(a) and 17(b) show the external and 
internal SD profiles respectively. The SD is essentially zero on the top surface, indicating that pressure oscillations generated inside the nozzle do not travel upstream. The $\mathrm{k}-\varepsilon$ and EASM models show the largest SD values inside the nozzle. Table 6 shows the normalized thrust and massflow for each turbulence model. Experimental thrust data was not available. The massflow values are very similar to the Mach 0.9, NPR 6 case, and the thrust values are generally lower. The k- $\varepsilon$ and EASM models produce the highest values of thrust of all the models.

Table 6: Comparison of normalized massflow and thrust for different turbulence models. "cc" refers to the $S-A$ rotation correction.

\begin{tabular}{|c|c|c|}
\hline $\begin{array}{c}\text { Mach 1.2, } \\
\text { NPR4 }\end{array}$ & $\begin{array}{c}\text { Normalized } \\
\text { Thrust }\end{array}$ & $\begin{array}{c}\text { Normalized } \\
\text { Massflow }\end{array}$ \\
\hline \hline Experiment & N/A & 0.9680 \\
\hline S-A (cc OFF) & 0.6980 & 0.9526 \\
\hline S-A (cc ON) & 0.6970 & 0.9527 \\
\hline SST & 0.7009 & 0.9527 \\
\hline EASM & 0.7044 & 0.9573 \\
\hline k- $\varepsilon\left(C_{\mu}\right.$ OFF) & 0.7173 & 0.9539 \\
\hline k- $\varepsilon\left(C_{\mu}\right.$ ON $)$ & 0.7123 & 0.9543 \\
\hline
\end{tabular}

\section{CONCLUSIONS}

CFD analyses of an axisymmetric circular-arc boattail nozzle at transonic Mach numbers have been performed to better understand the effects of high-speed nozzle geometries on the nozzle internal flow and the surrounding boattail regions. The converging-divergeing nature of the "Configuration 2" geometry operating at lower-than-design NPRs provides a challenging flowfield for studying the capabilities of Wind's turbulence models to predict nozzle aerodynamics. Boattail and internal nozzle pressure distributions computed with the Wind code have been compared with experimental data obtained in the NASA Langley 16-Foot Transonic Tunnel. Using a range of turbulence models, including an Explicit Algebraic Stress model, the experimental data pressure profiles on one nozzle geometry have been predicted fairly accurately. Analyzing the Wind steadystate solutions (variable timestepping) indicates that all cases exhibit variations in flow properties (failure to converge to a steady-state solution) that affects the pressure distribution on the external surface. The peaks in the apparent unsteadiness manifest themselves at the start of the curved portion of the boattail on the top surface, and in the nozzle just forward of where the shock meets the wall.

Subsequent time-accurate (constant timestepping) analysis on the Mach 0.9, NPR 4 case using the SST model indicates that the true unsteadiness is quite less, and the numerical instabilities associated with using variable timestepping on a problem with separated regions leads to an inability to obtain a converged solution. The initial motivation for attempting time-accurate calculations was to obtain a more consistent set of instantaneous flowfield solutions for time-averaging of the apparent unsteady problem. However, the timeaccurate calculations, with constant time stepping employed (in contrast to the local time stepping used by the steady-state solver) enabled a nearly converged solution to be obtained. While the RANS technique should be expected to provide a steady-state solution, it appears that for all of these problems with large scale flow separations, the time-accurate solver with constant timestepping is better able to remove numerical instabilities associated with these large separated flow regions than the local time-stepping approach of the steady-state solver. Nevertheless, the SST turbulence model best predicts the internal and external mean pressure distributions for all cases studied. The Chien k- $\varepsilon$ and EASM $\mathrm{k}-\varepsilon$ models predict the nozzle internal shock to occur upstream compared with other model predictions, resulting in a larger separation region inside the nozzle.

\section{ACKNOWLEDGEMENTS}

This work was conducted under grant NCC3-922, sponsored by the Propulsion Research and Technology Project of NASA's Next Generation Launch Technology Program. Help from the following individuals made this work possible: John Slater, John Wolter, Jim DeBonis, and Rickey Shyne.

\section{REFERENCES}

1) Nelson, C.C. and Power, G.D., "CHSSI Project CFD7: The NPARC Alliance Flow Simulation System," AIAA Paper 2001-0594, January 2001.

2) Aeronautical Facilities Catalogue, Wind Tunnels, NASA-RP-1132, Volume 1, National Aeronautics and Space Administration, January 1985.

3) Carson, G. T., Jr. and Lee, E. E., Jr., "Experimental and Analytical Investigation of Axisymmetric Supersonic Cruise Nozzle Geometry at Mach Numbers from 0.60 to 1.30 ," NASA TP-1953, 1981.

4) Carlson, J. R., "Computational Prediction of Isolated Performance of an Axisymmetric Nozzle at Mach 
Number 0.90," NASA TM-4506, February 1994.

5) Spalart, P.R. and Allmaras, S.R., "A One-Equation Turbulence Model for Aerodynamic Flows," AIAA Paper 1992-0439, January 1992.

6) Menter, F.R., "Two-Equation Eddy Viscosity Turbulence Models for Engineering Applications," AIAA Journal, Vol. 32, No. 8, August 1994, pp. 1598-1605.

7) Chien K.Y., "Predictions of Channel and Boundarylayer Flows with a Low-Reynolds-Number Turbulence Model," AIAA Journal, Vol 20, No. 1, pp.33-38.

8) Rumsey, C.L., and Gatski, T.B., and Morrison, J.H., "Turbulence Model Predictions of Strongly Curved Flow in a U-Duct," AIAA Journal, Vol. 38, No. 8., 2000, pp. 1394-1402.

9) Yoder, D. A., "Initial Evaluation of an Algebraic Reynolds Stress Model For Compressible Turbulent Shear Flows," AIAA Paper 20030548, January 2003.
10) Sarkar, S., Erlebacher, G., and Kreiss, H.O., "The Analysis and Modeling of Dilatational Terms in Compressible Turbulence," Journal of Fluid Mechanics, Vol. 227, 1991, pp. 473-493.

11) Rodi, W., "A New Algebraic Relation for Calculating the Reynolds Stresses," Z. Ang. Math. Mech., Vol. 56, 1976, pp. T219-T221.

12) GRIDGEN Version 13, User Manual, Pointwise, Inc. 1998, Bedford, Texas.

13) Ying, S. X., Spaid, F.W., McGinley, C.B., and Rumsey, C.L., "Investigation of Confluent Boundary Layers in High-Lift Flows," Journal of Aircraft, Vol. 36, No. 3, May-June 1999, pp. 550562.

14) Georgiadis, N.J., Rumsey, C.L., Yoder, D.A., and Zaman, K.B.M.Q., "Effects of RANS Turbulence Modeling on Calculations of Lobed Nozzle Flowfields," AIAA Paper 2003-1271, January 2003.

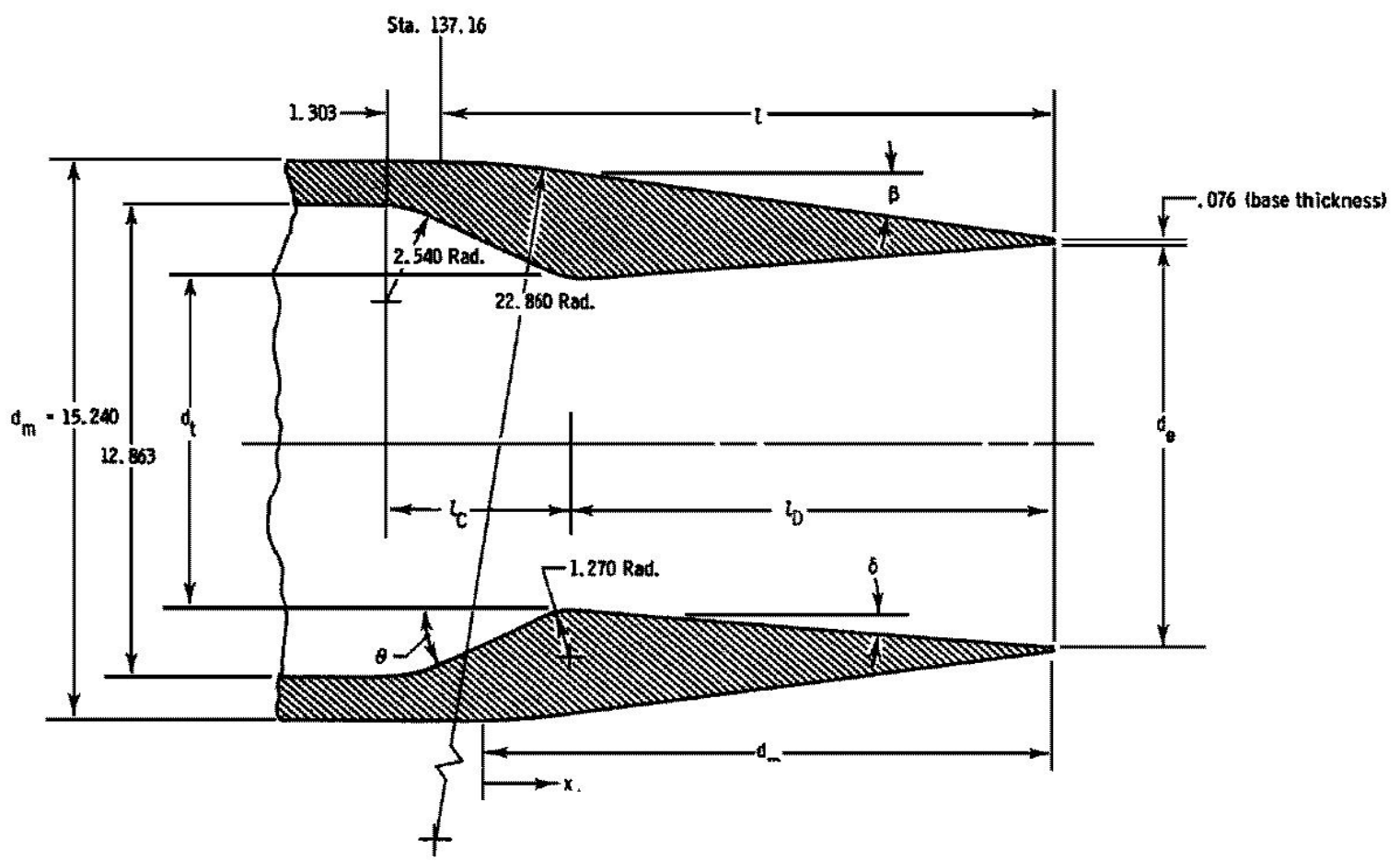

Figure 1: Schematic of nozzle geometry (units of centimeters). 


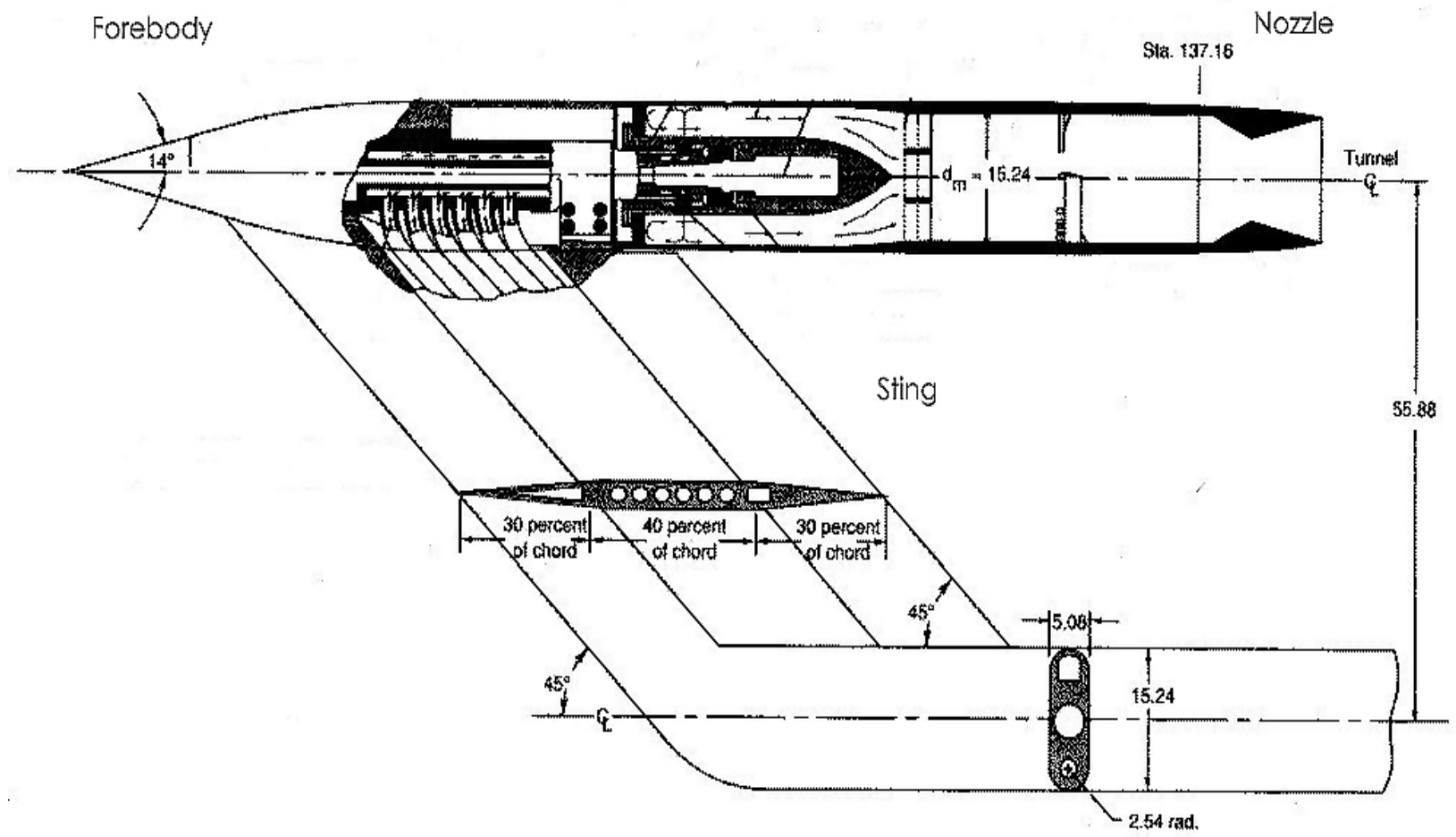

Figure 2: Schematic of NASA Langley experimental rig (forebody/nozzle/support).

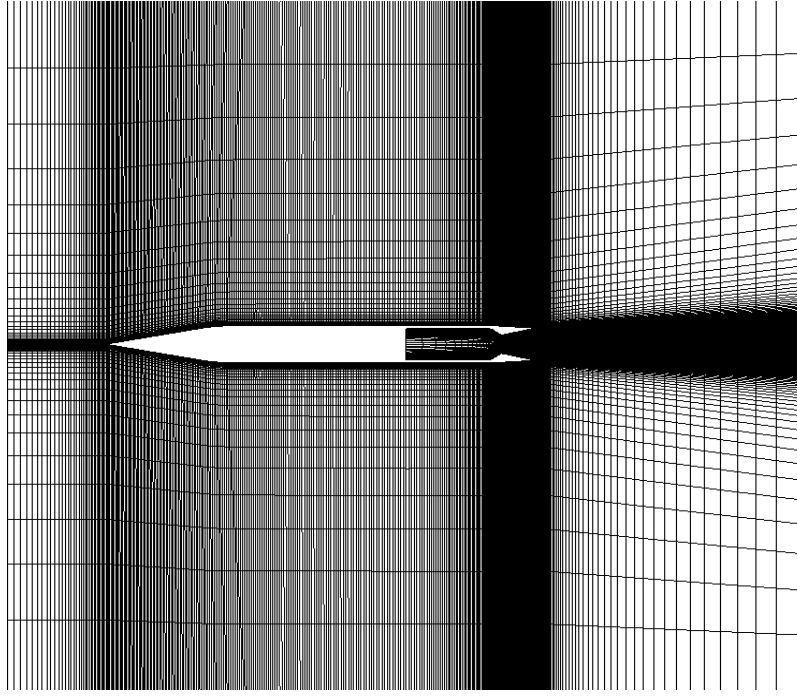

Figure 3(a): Computational grid for "Configuration 2" forebody and nozzle structure.

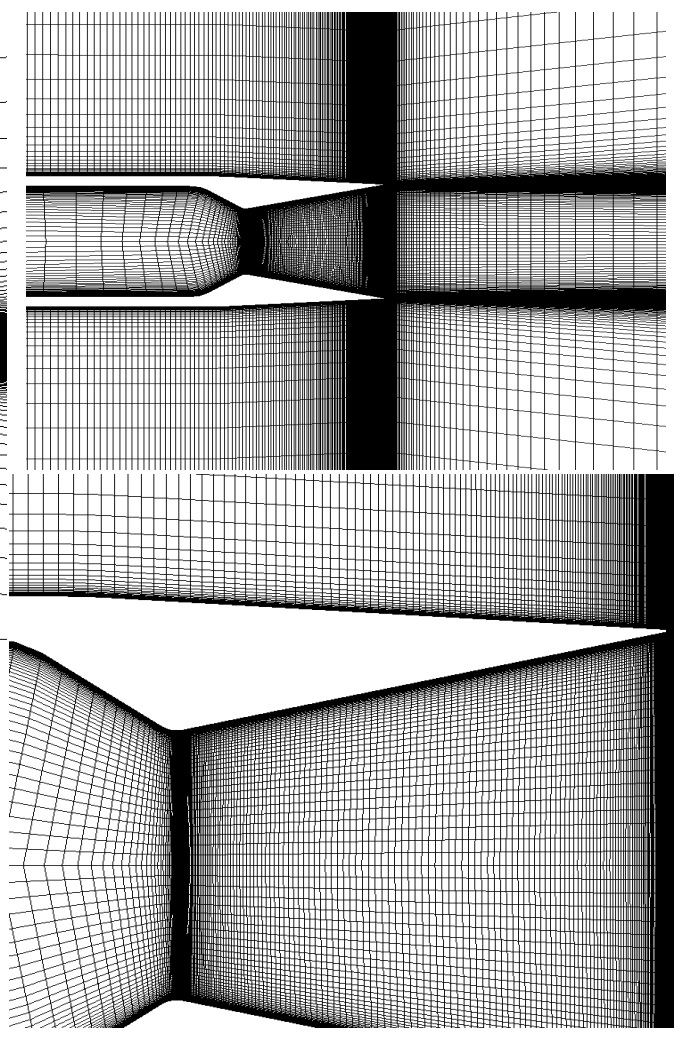

Figure

3(b):

Close-up view of the nozzle exit.

Figure

3(c):

Close-up

nozzle

afterbody. 


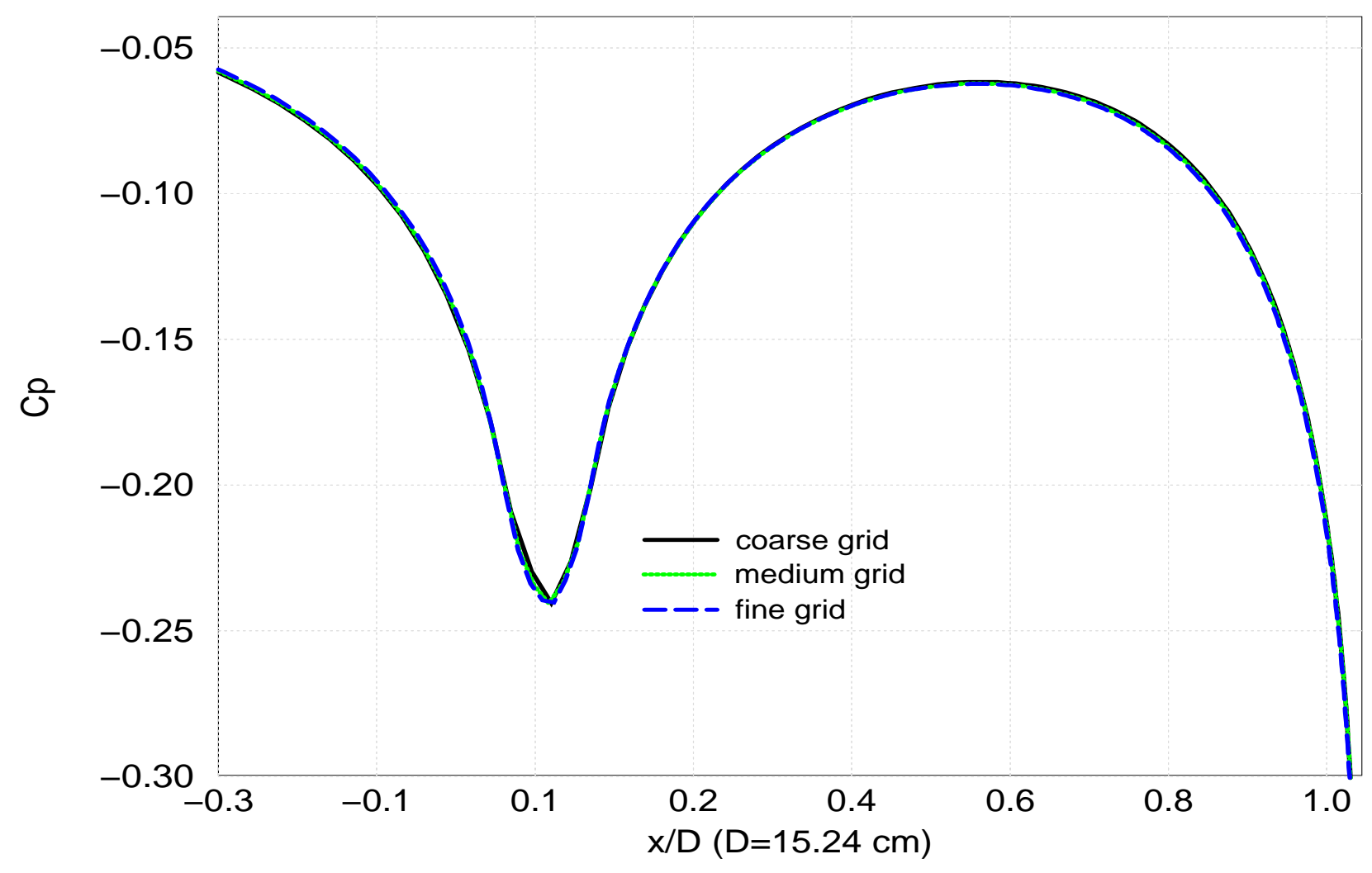

Figure 4: Grid dependence plot of mean Cp values on the external surface for coarse, medium and fine grids.

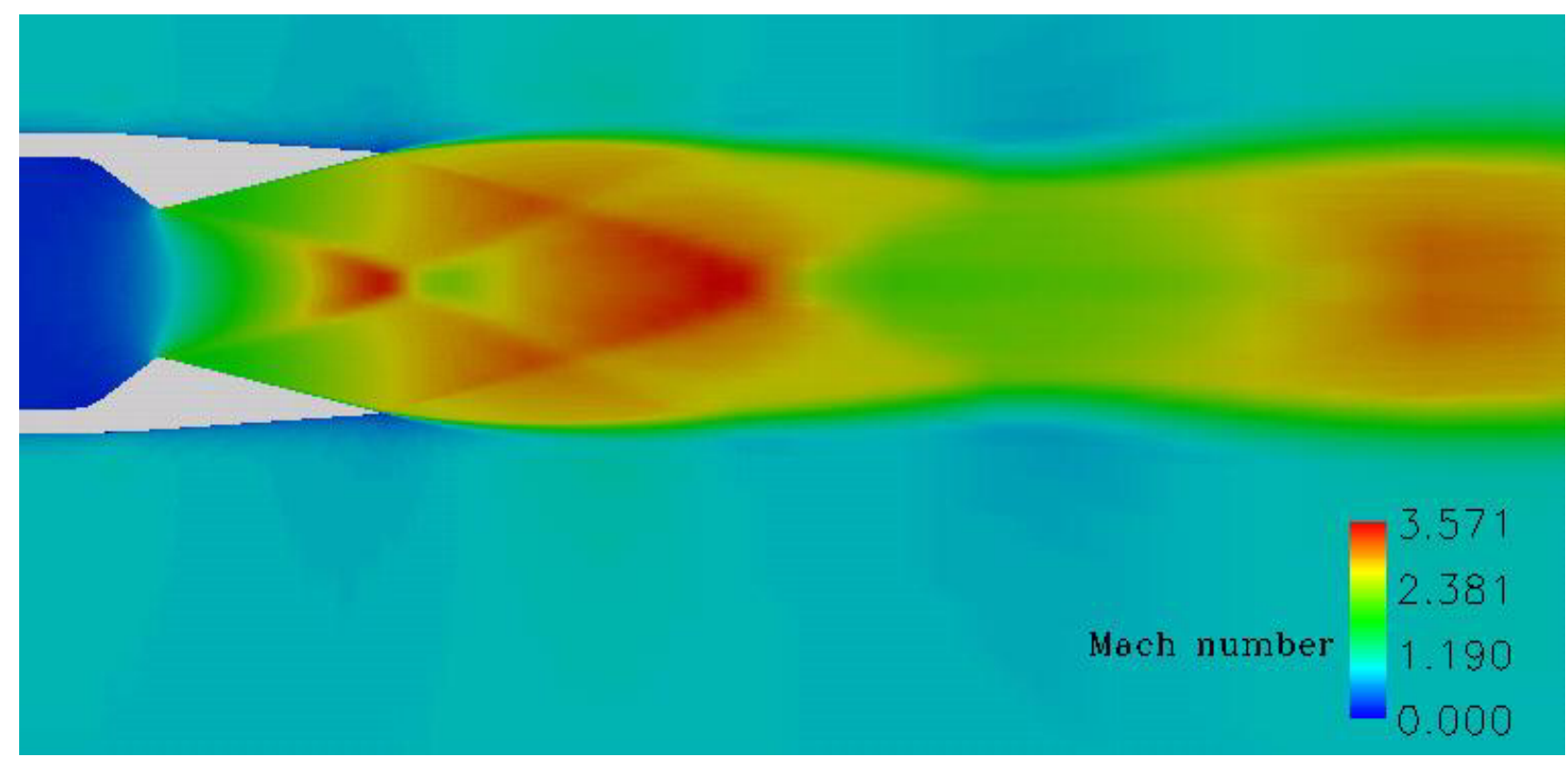

Figure 5: Mach number contours using the Spalart-Allmaras model at the design NPR of 21.23 and Mach number 0.9. 


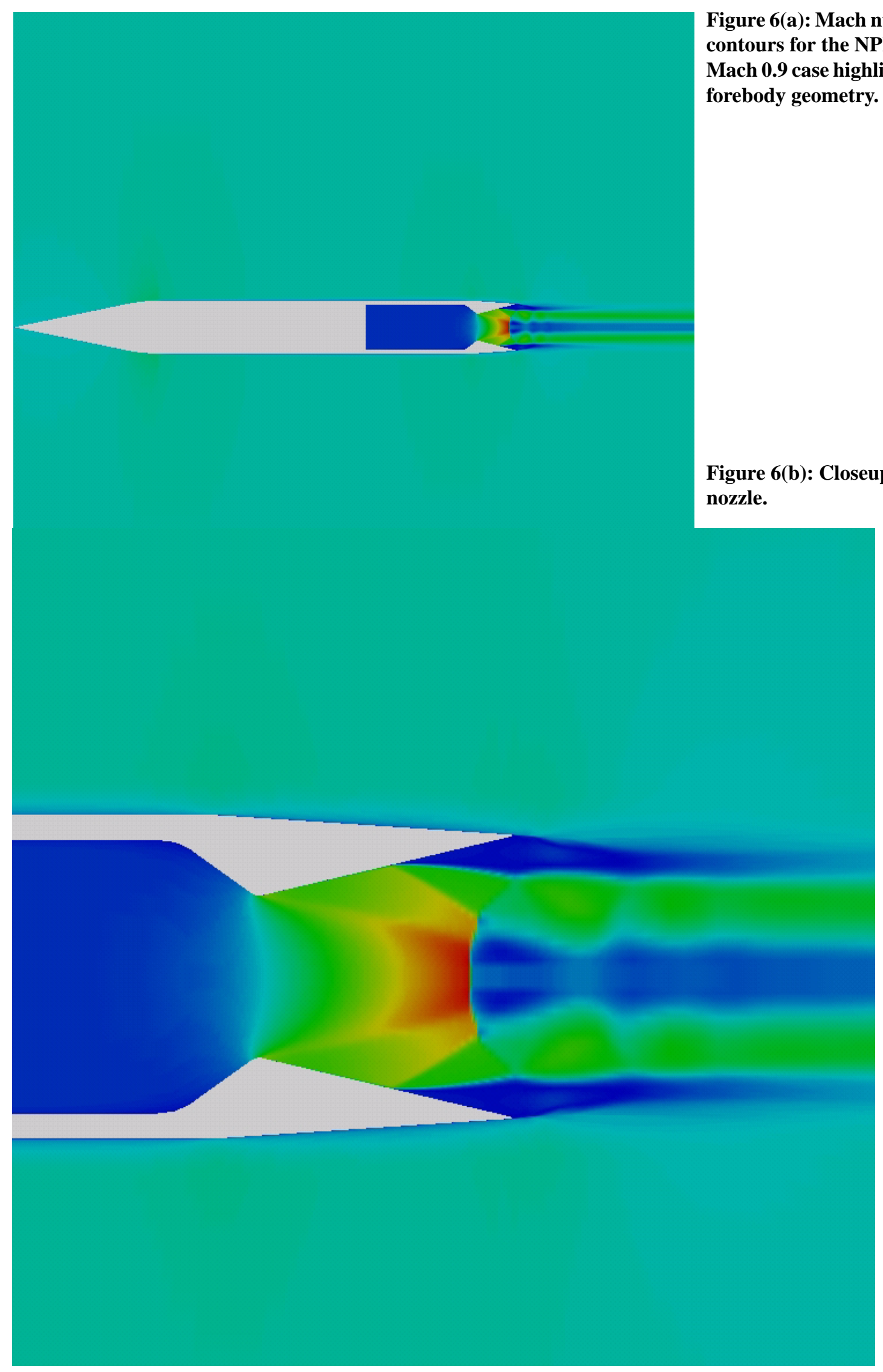




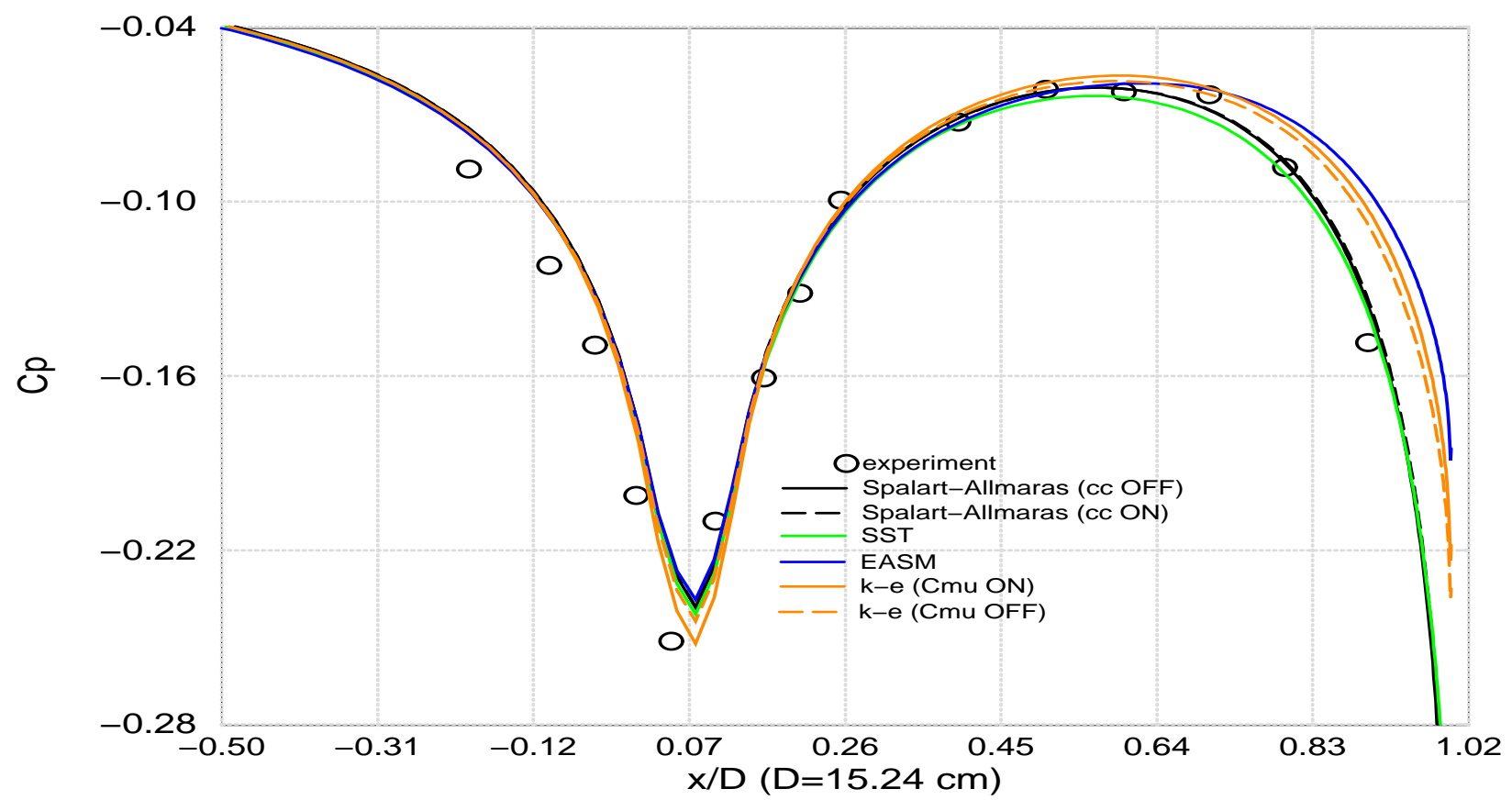

Figure 7(a): Mean Cp profiles on the external surface for the NPR=4, Mach 0.9 case.

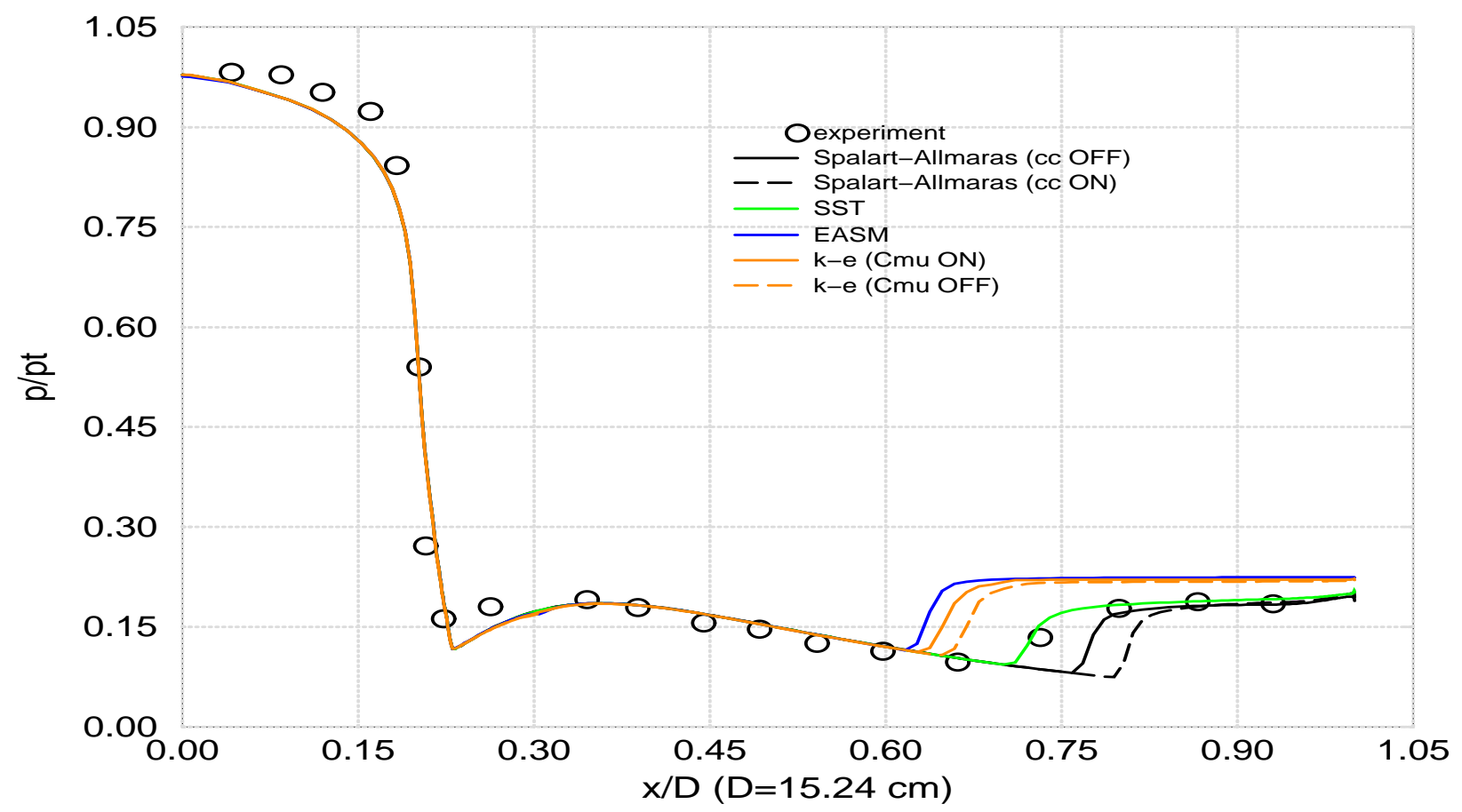

Figure 7(b): Pressure distribution on the internal surface for the NPR=4, Mach 0.9 case. 


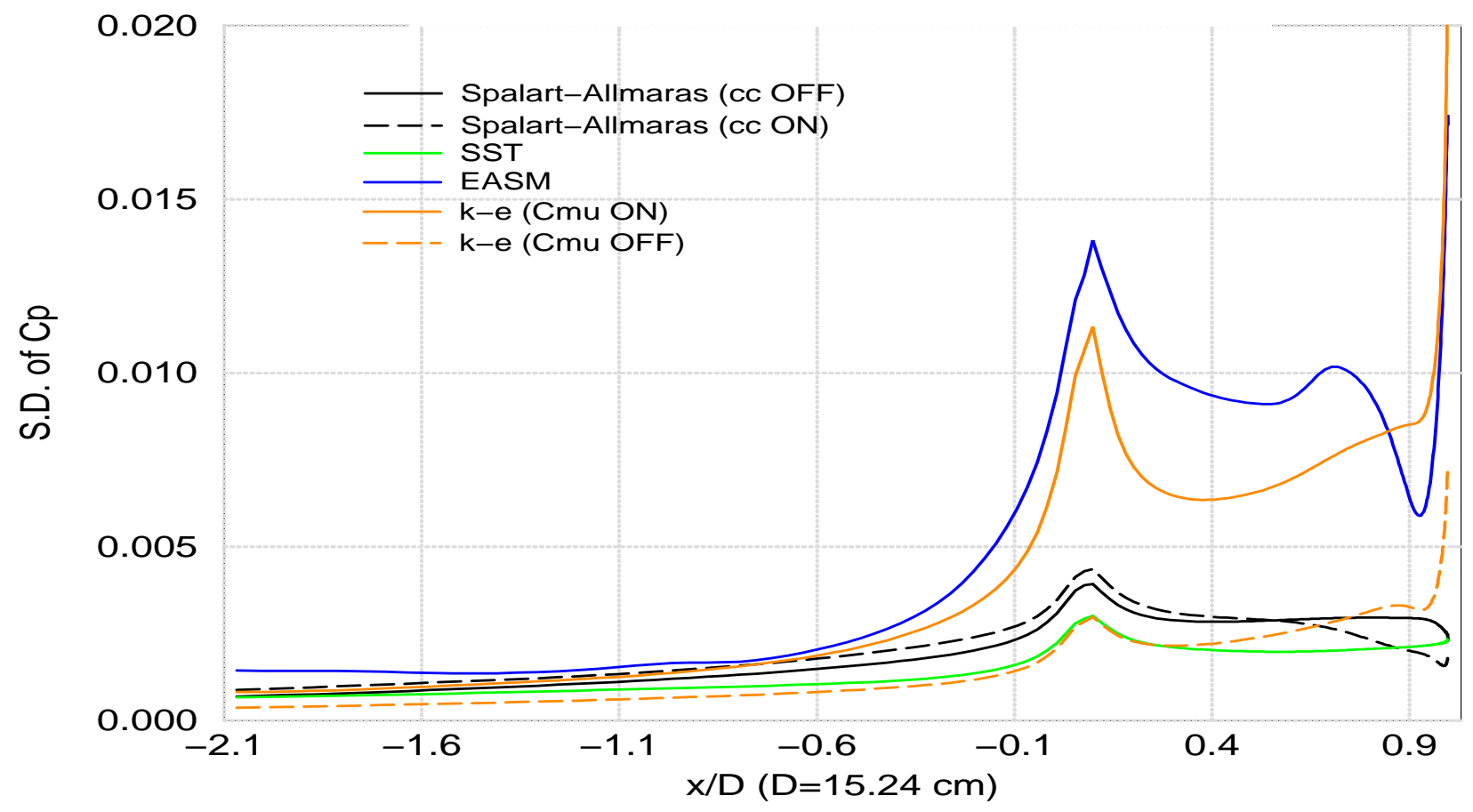

Figure 8(a): Standard Deviation curves of $\mathrm{Cp}$ on the external surface for all turbulence models at NPR=4, Mach 0.9.

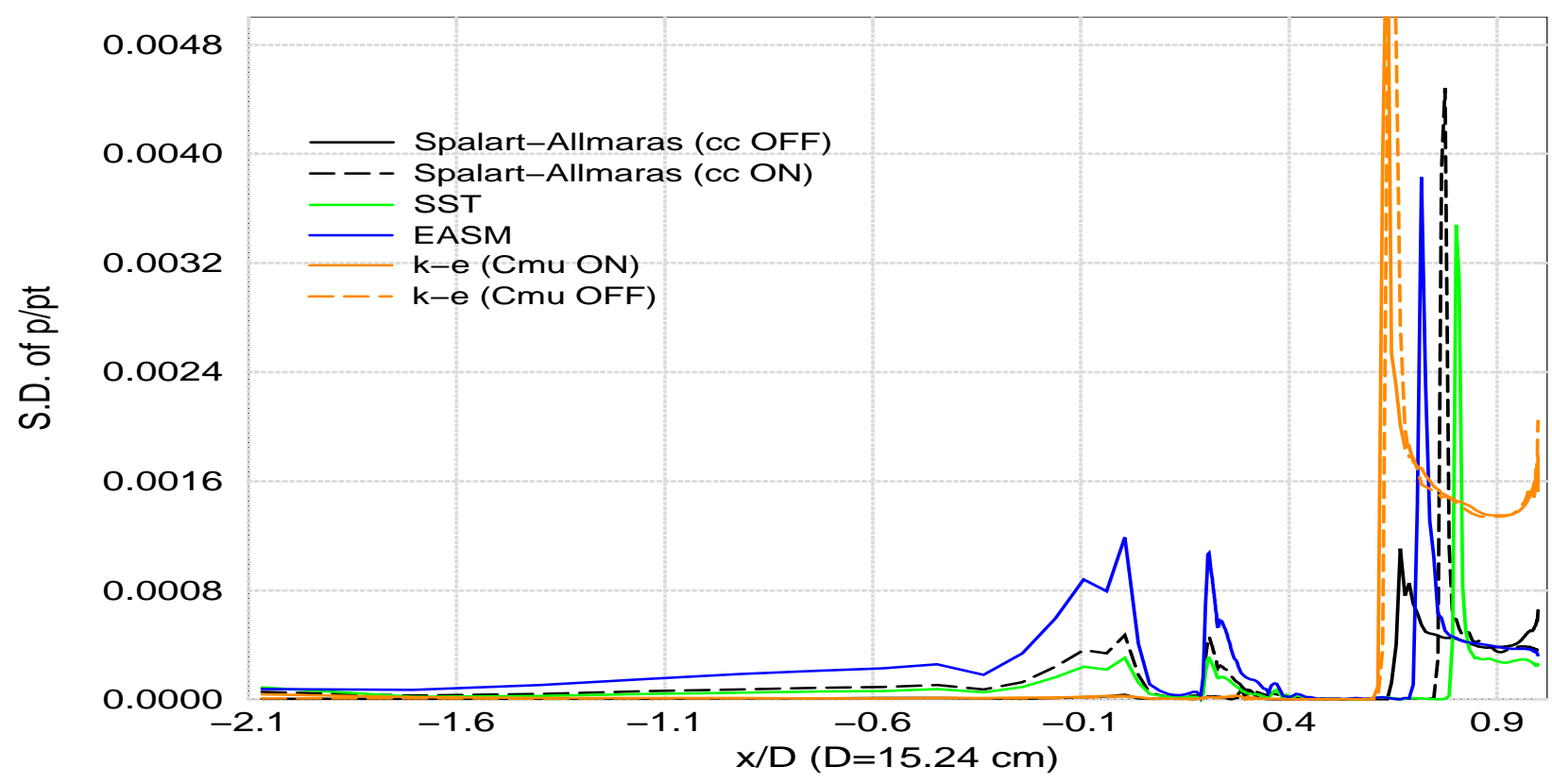

Figure 8(b): Standard Deviation curves of $p / p_{t}$ on the internal surface for all turbulence models at $N P R=4$, Mach 0.9. 


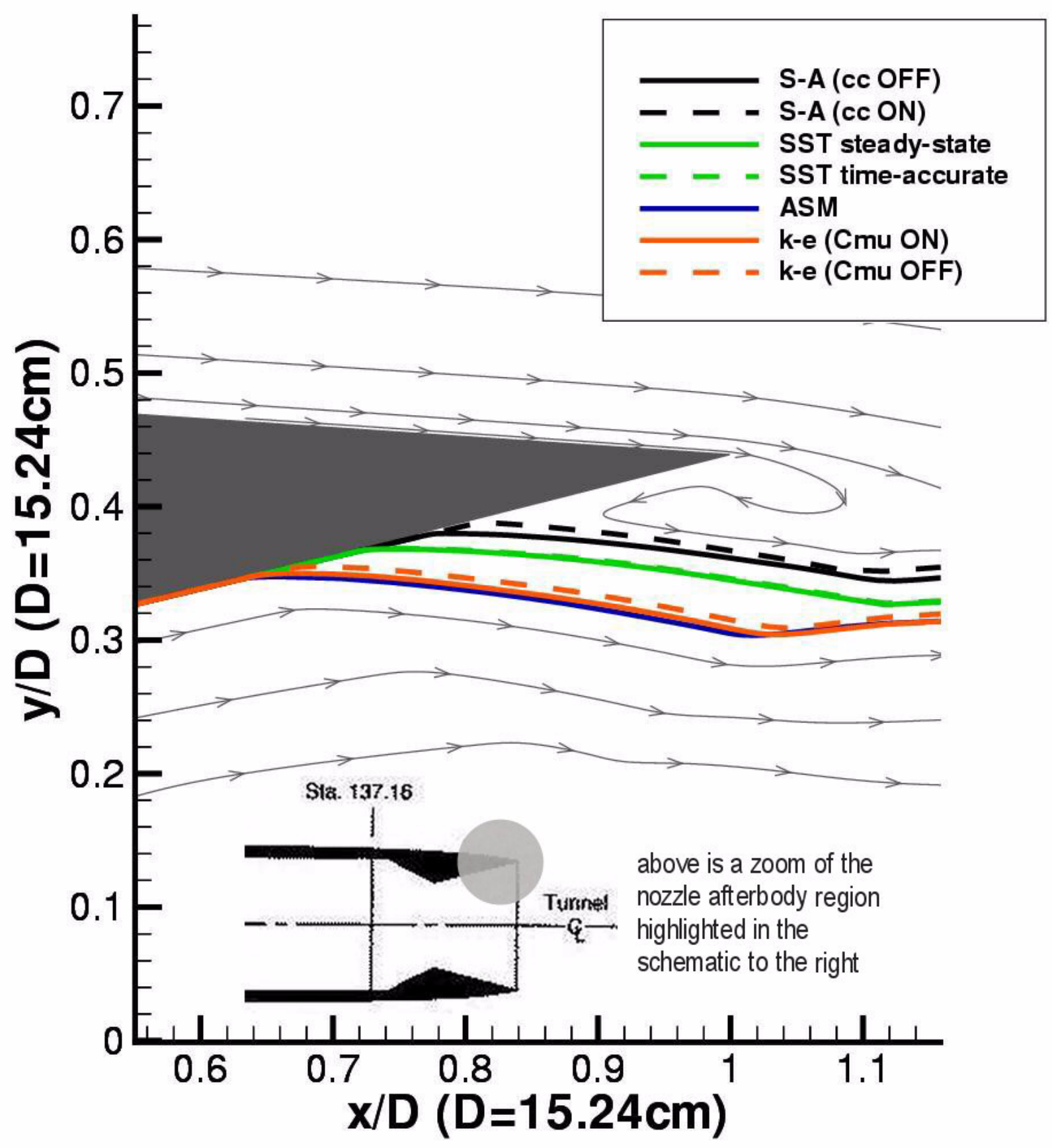

Figure 9: Streamlines defining the separation region for the Mach 0.9, NPR 4 case. Streamlines start at the 7th gridpoint off the wall in the nozzle throat. The shaded region indicates the nozzle afterbody structure. The gray streamlines (with vectors) are reference streamlines. 


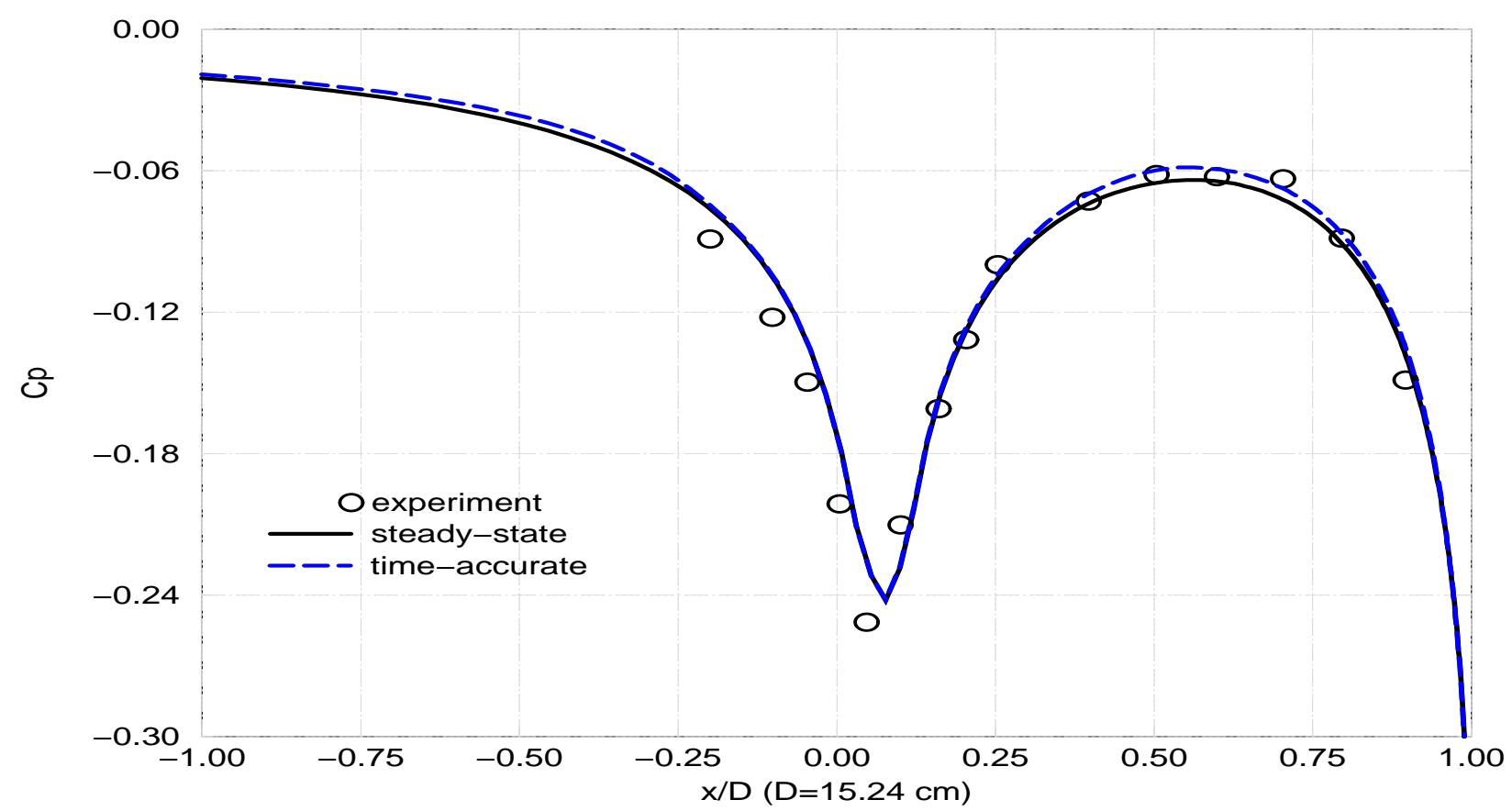

Figure 10(a): Cp curves on external surface for Mach 0.9, NPR 4 with the SST model.

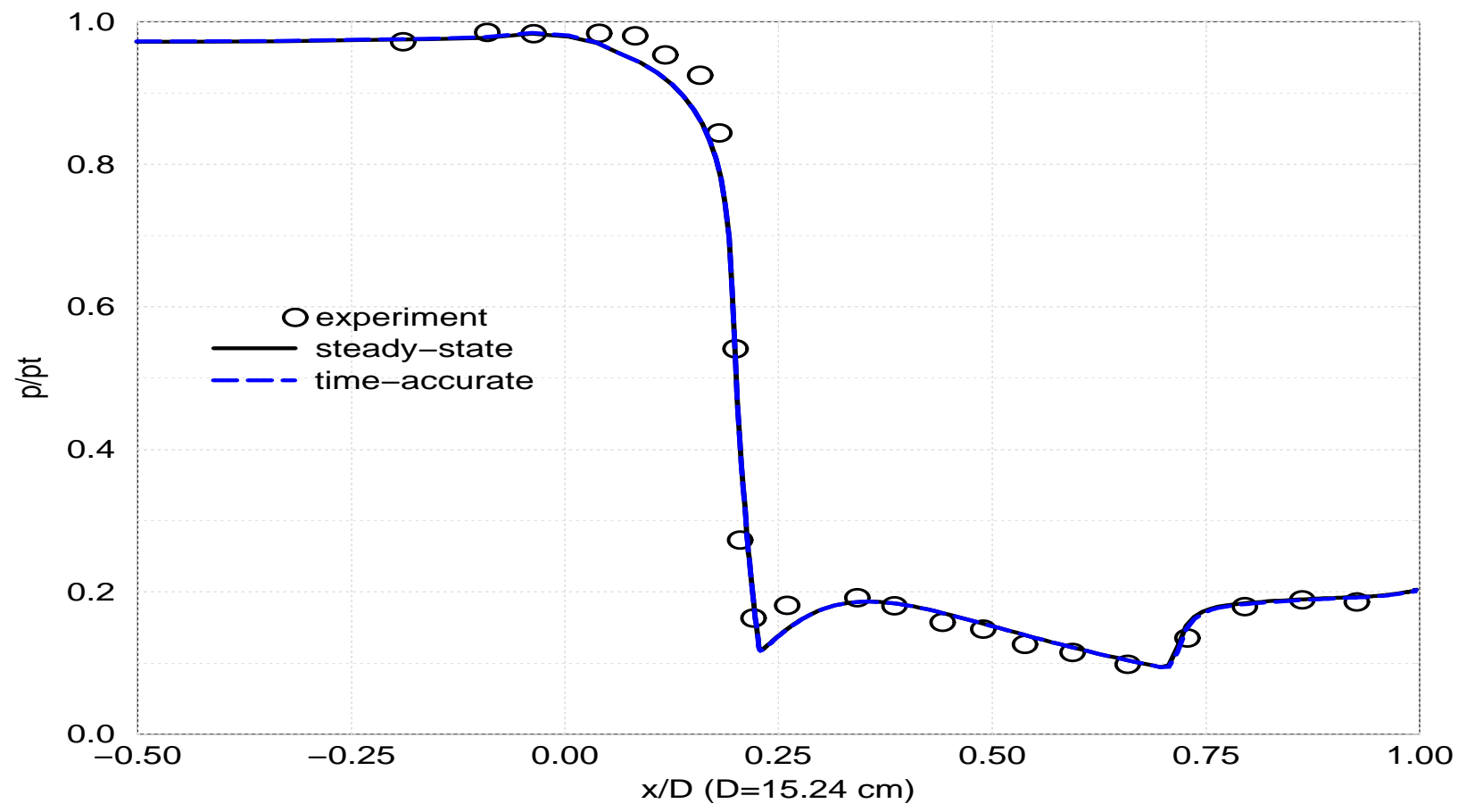

Figure 10(b): Normalized pressure $\left(\mathrm{p} / \mathrm{p}_{\mathrm{t}}\right)$ curves on internal surface for Mach 0.9, NPR 4 with the SST model. 


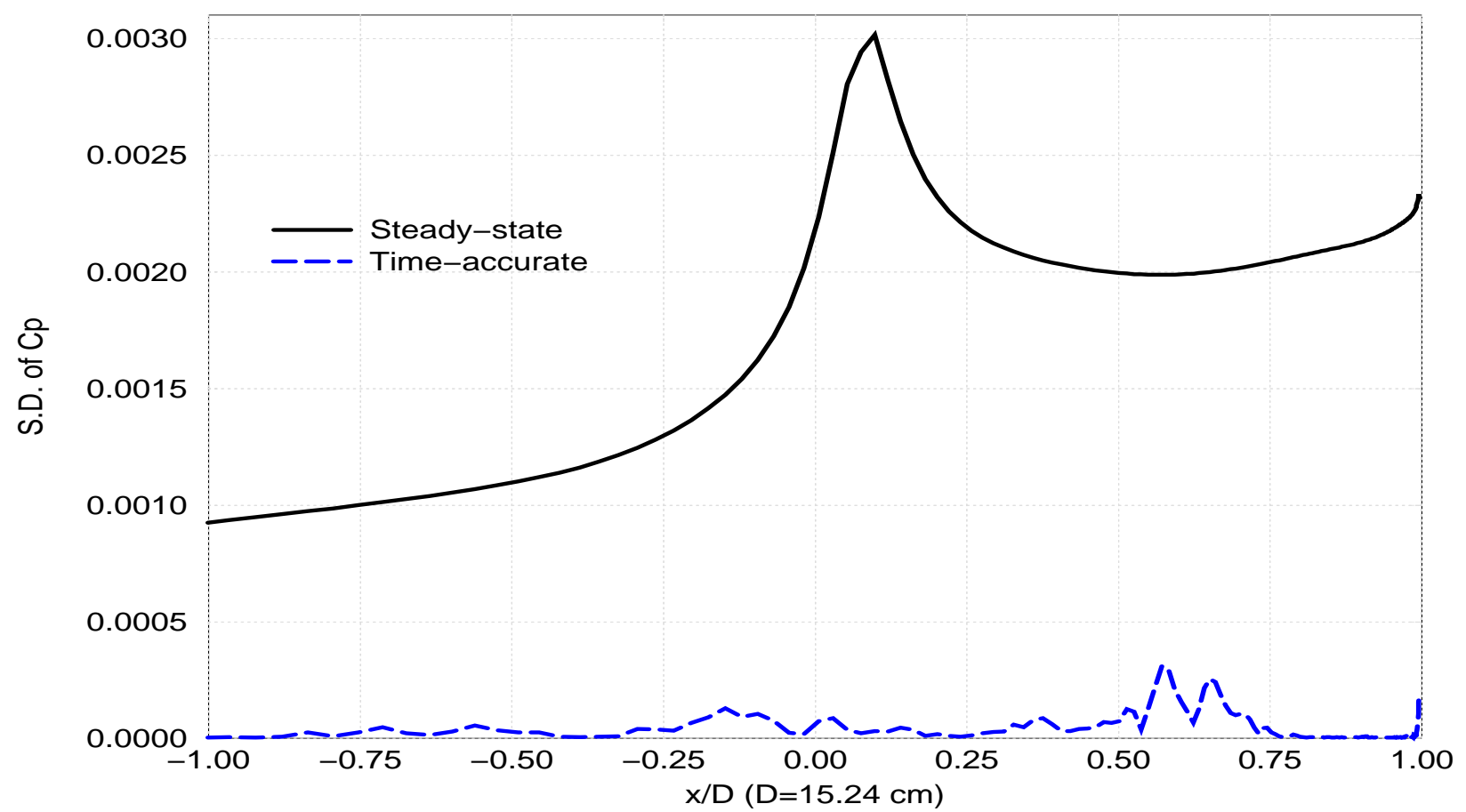

Figure 11(a): Standard Deviation curves of $\mathrm{Cp}$ on the external surface at Mach 0.9, NPR=4.

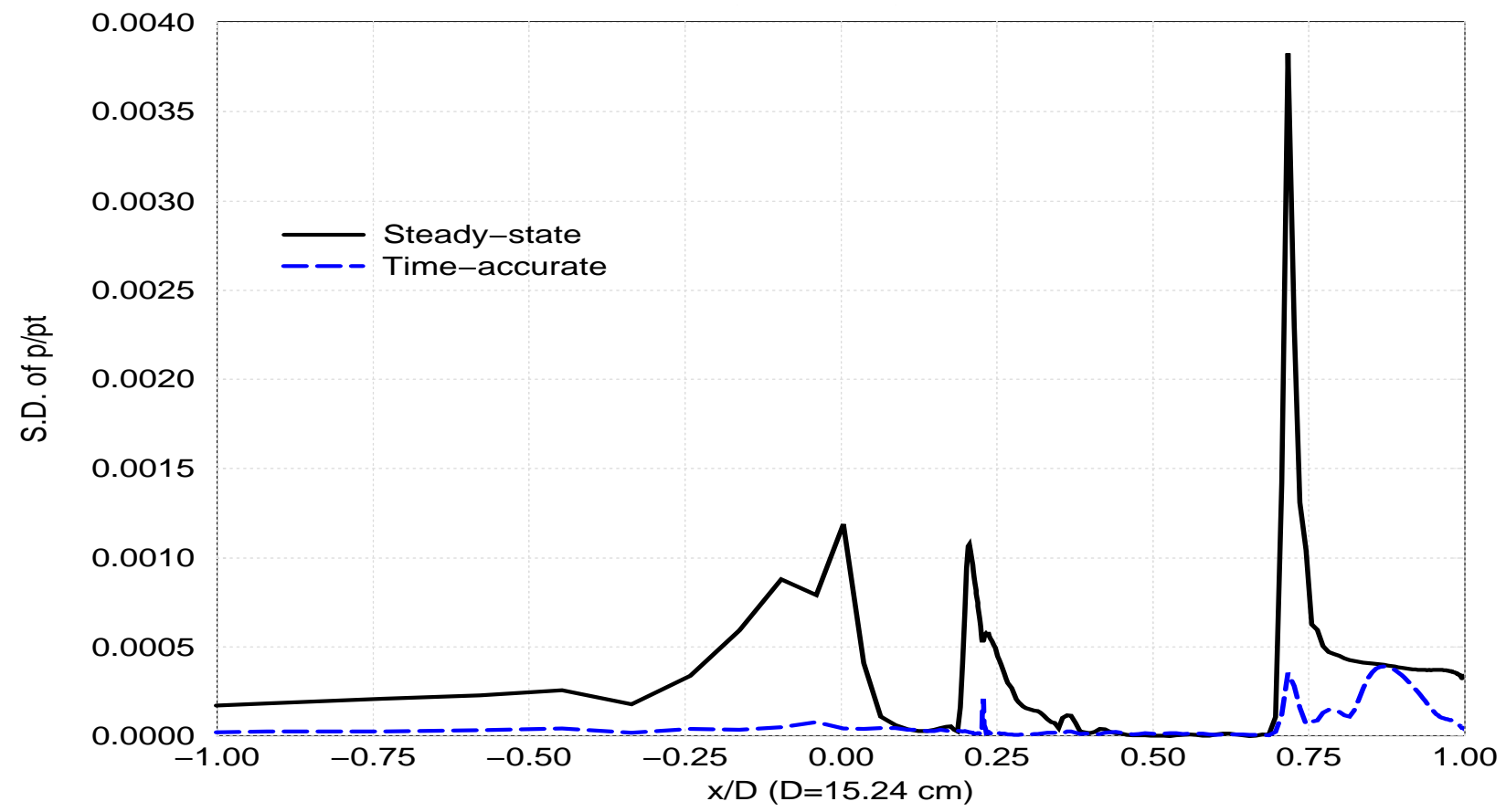

Figure 11(b): Standard Deviation curves of $p / p_{t}$ on the internal surface at Mach $0.9, N P R=4$. 


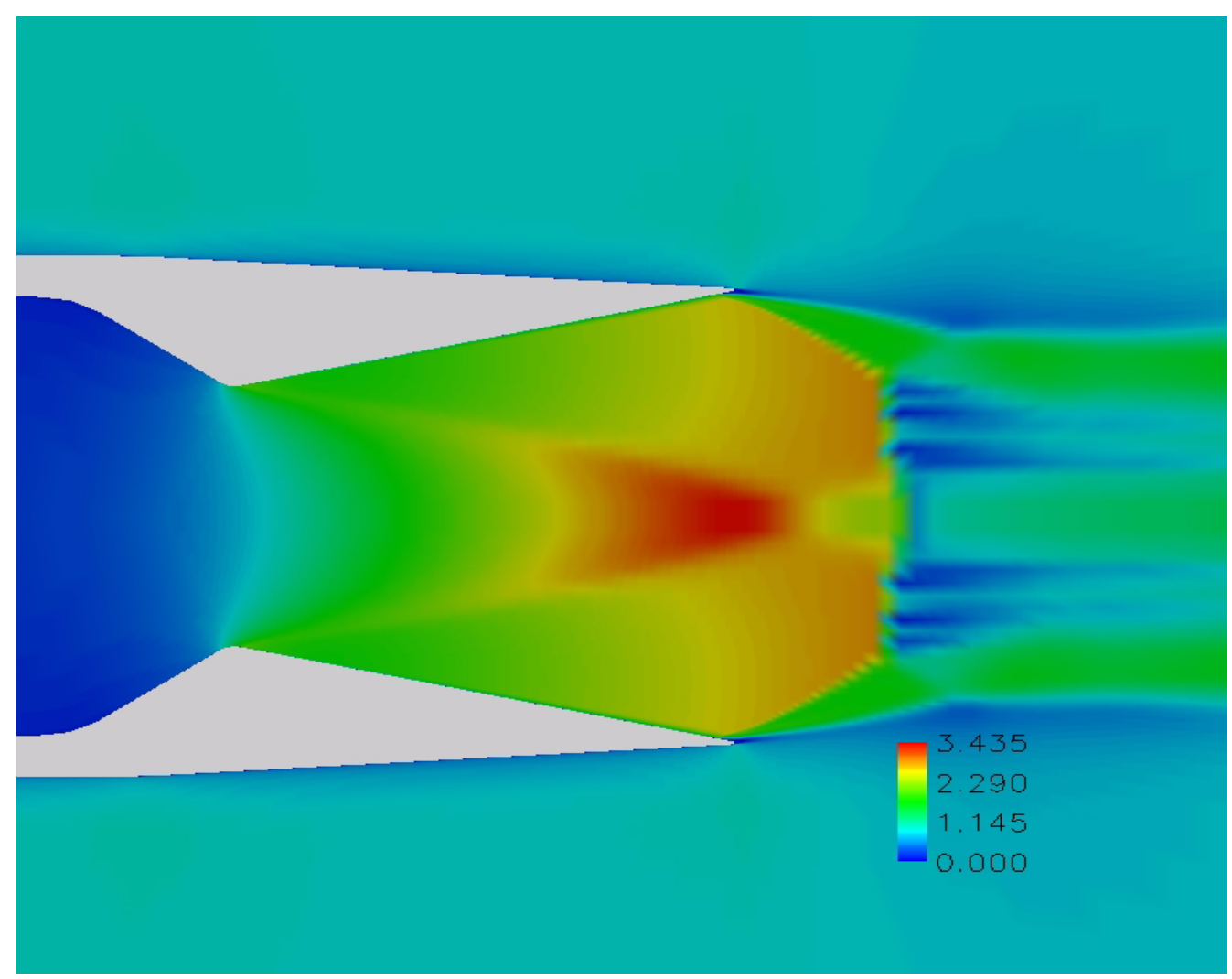

Figure 12: Mach number contours at an NPR of 6 and Mach number 0.9 with the Spalart-Allmaras model.

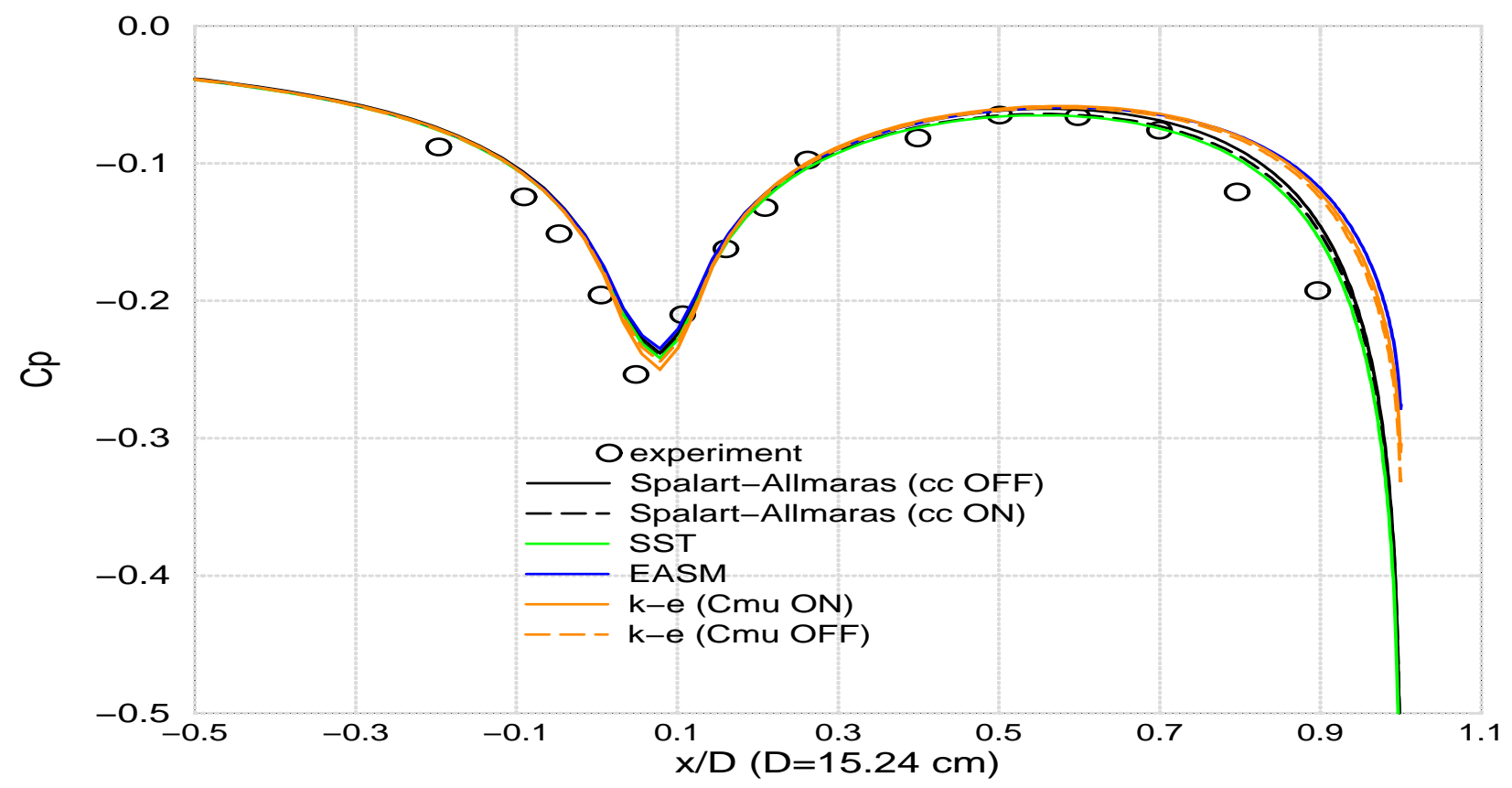

Figure 13(a): Mean Cp profiles on the external surface at an NPR of 6 and Mach number of 0.9. 


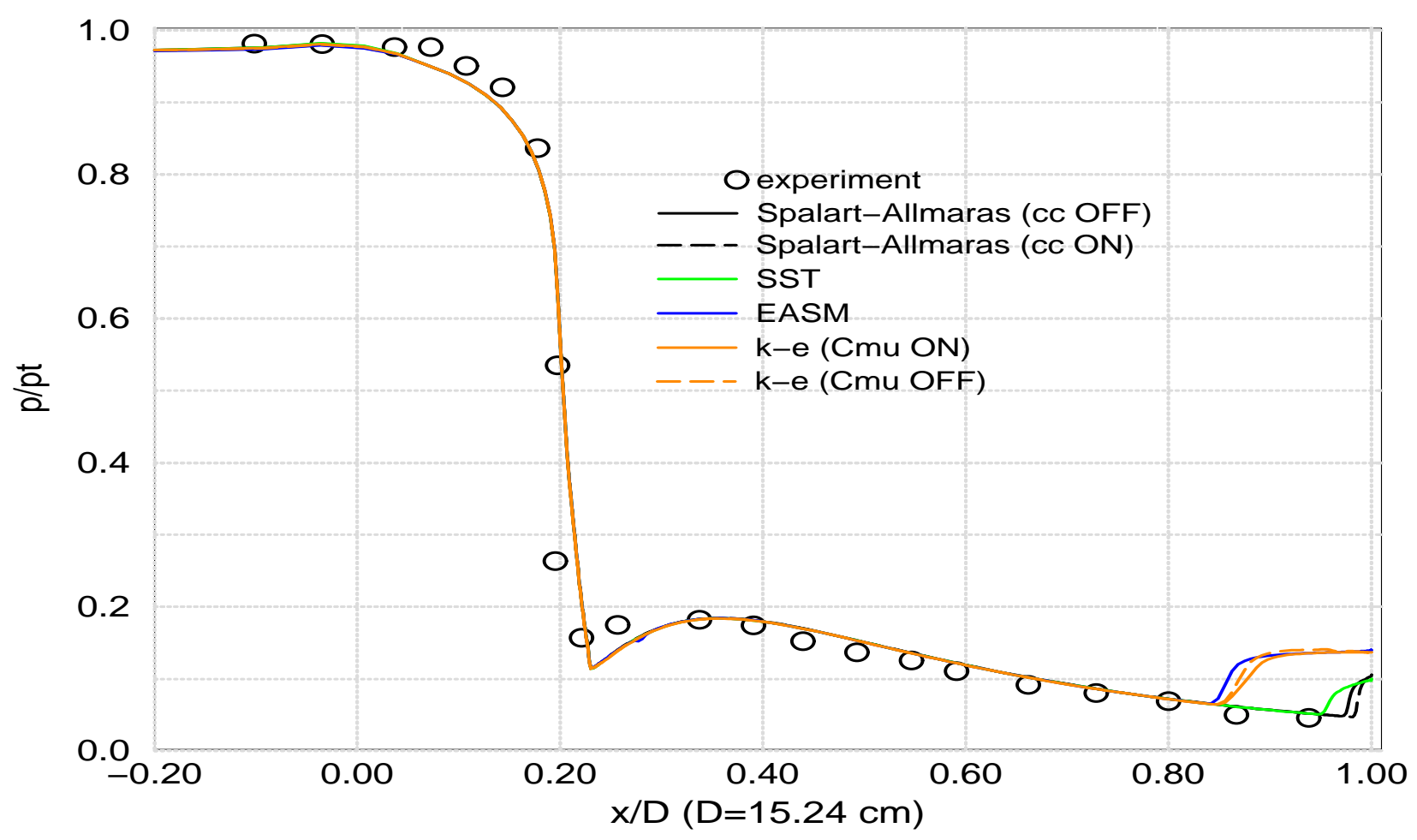

Figure 13(b): Mean p/p $p_{t}$ profiles on the internal nozzle surface at an NPR of 6 and Mach number of 0.9 .

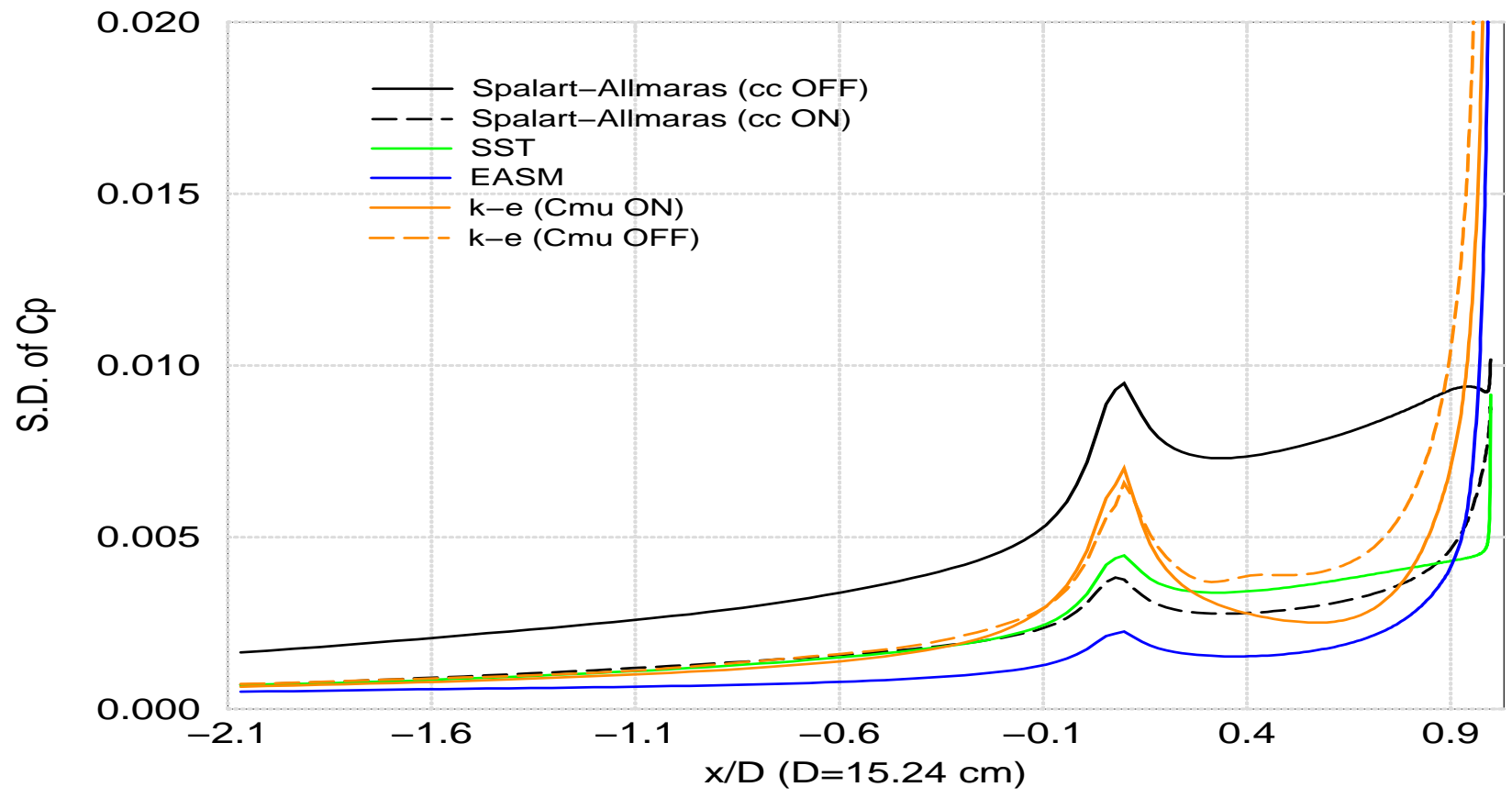

Figure 14(a): Standard Deviation curves of $\mathrm{Cp}$ on the external surface for all turbulence models at Mach 0.9, NPR=6. 


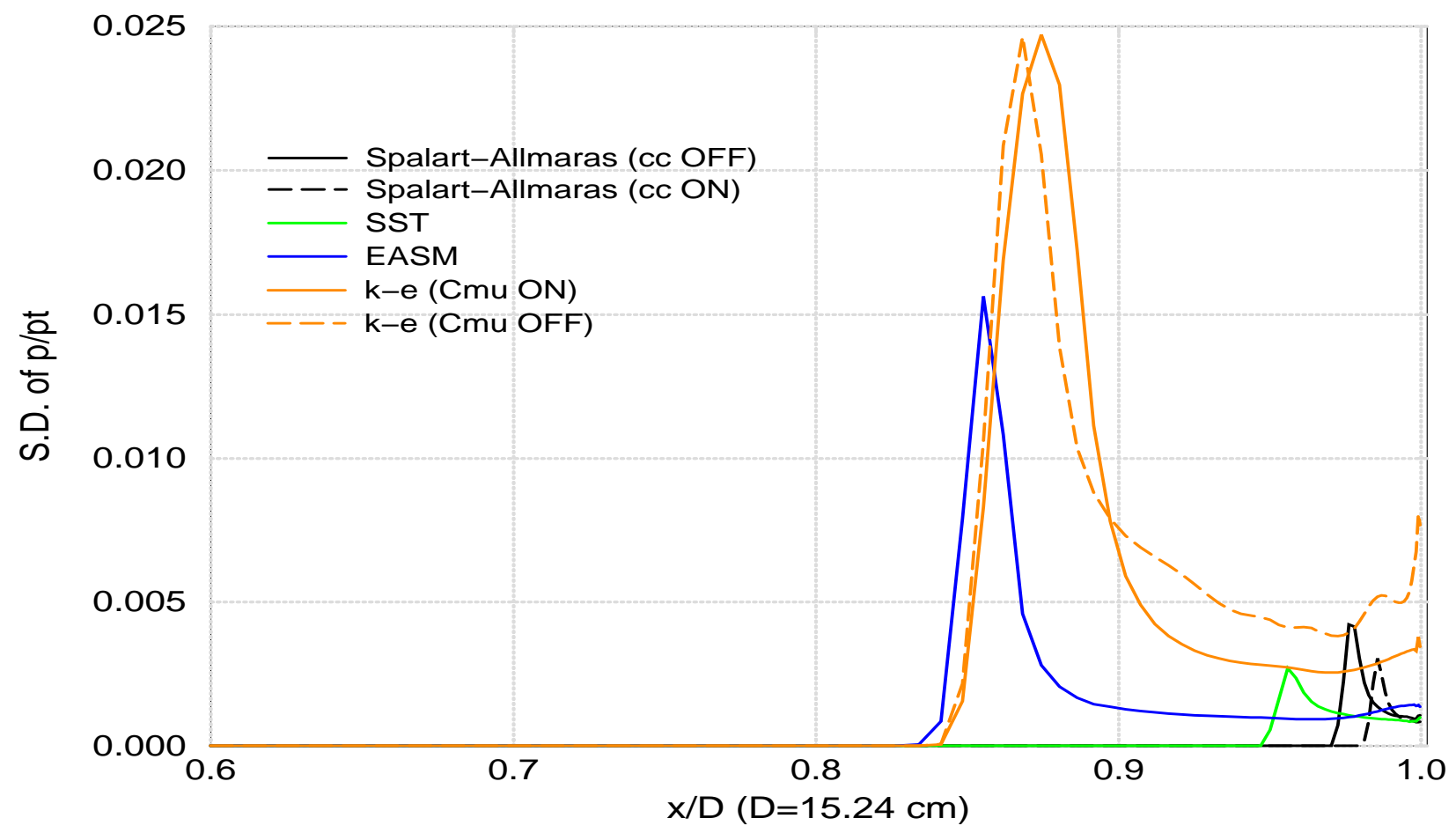

Figure 14(b): Standard Deviation curves of $p / p_{t}$ on the internal surface for all turbulence models at Mach 0.9 , NPR=6.

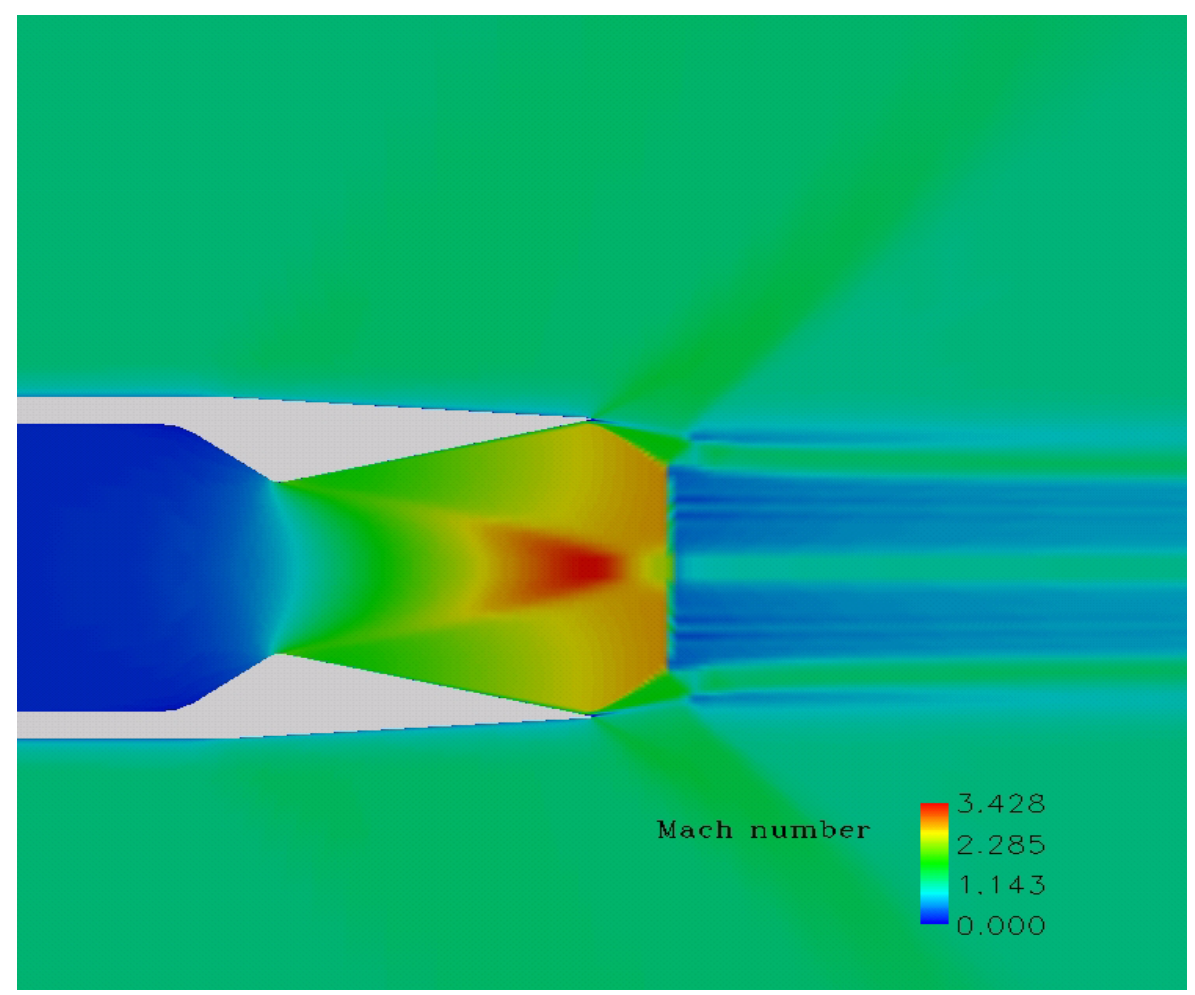

Figure 15: Mach number contours at an NPR of 4 and Mach number 1.2 with the Spalart-Allmaras model. 


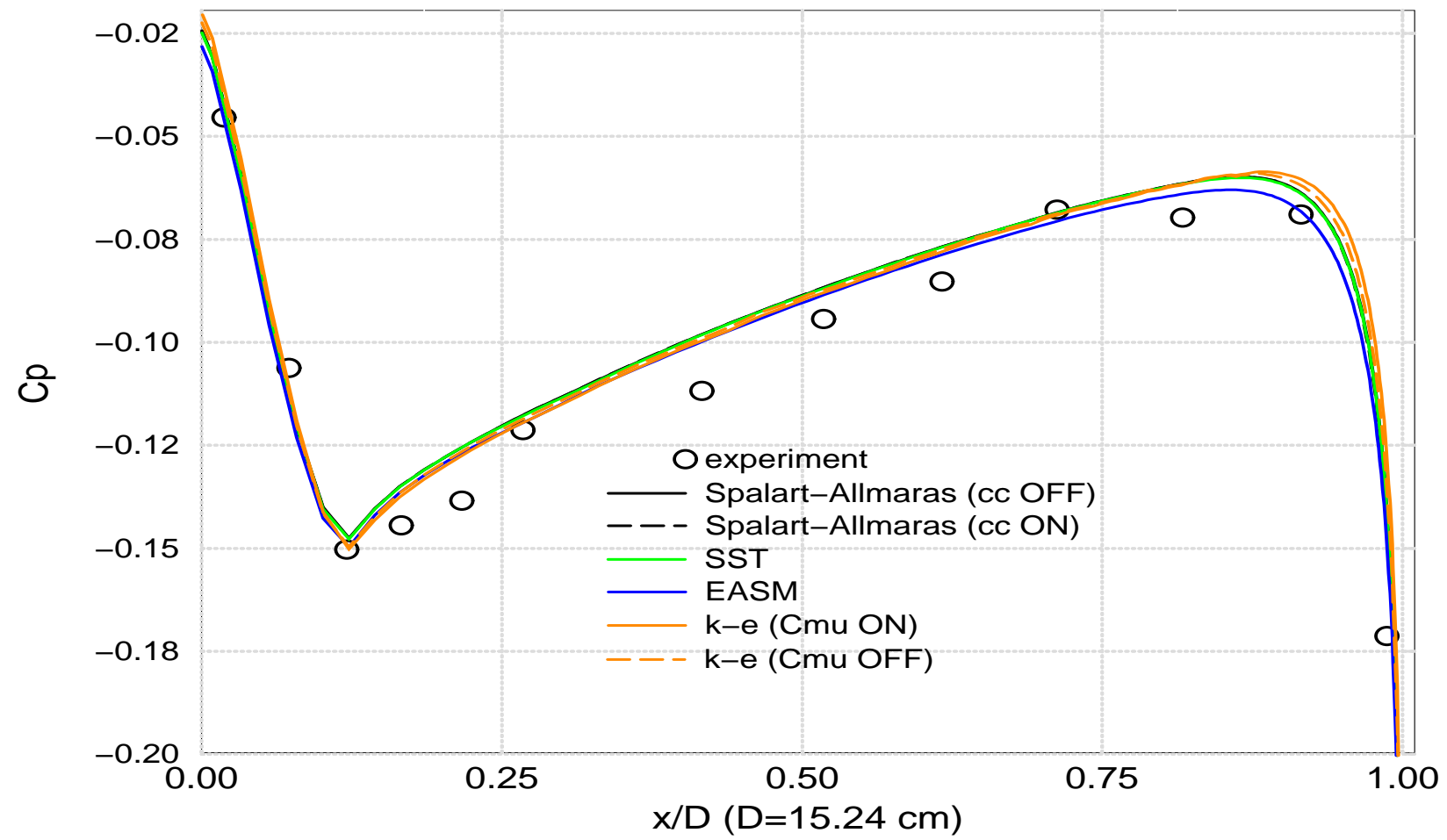

Figure 16(a): Mean Cp profiles on the external surface at an NPR of 4 and Mach number of 1.2.

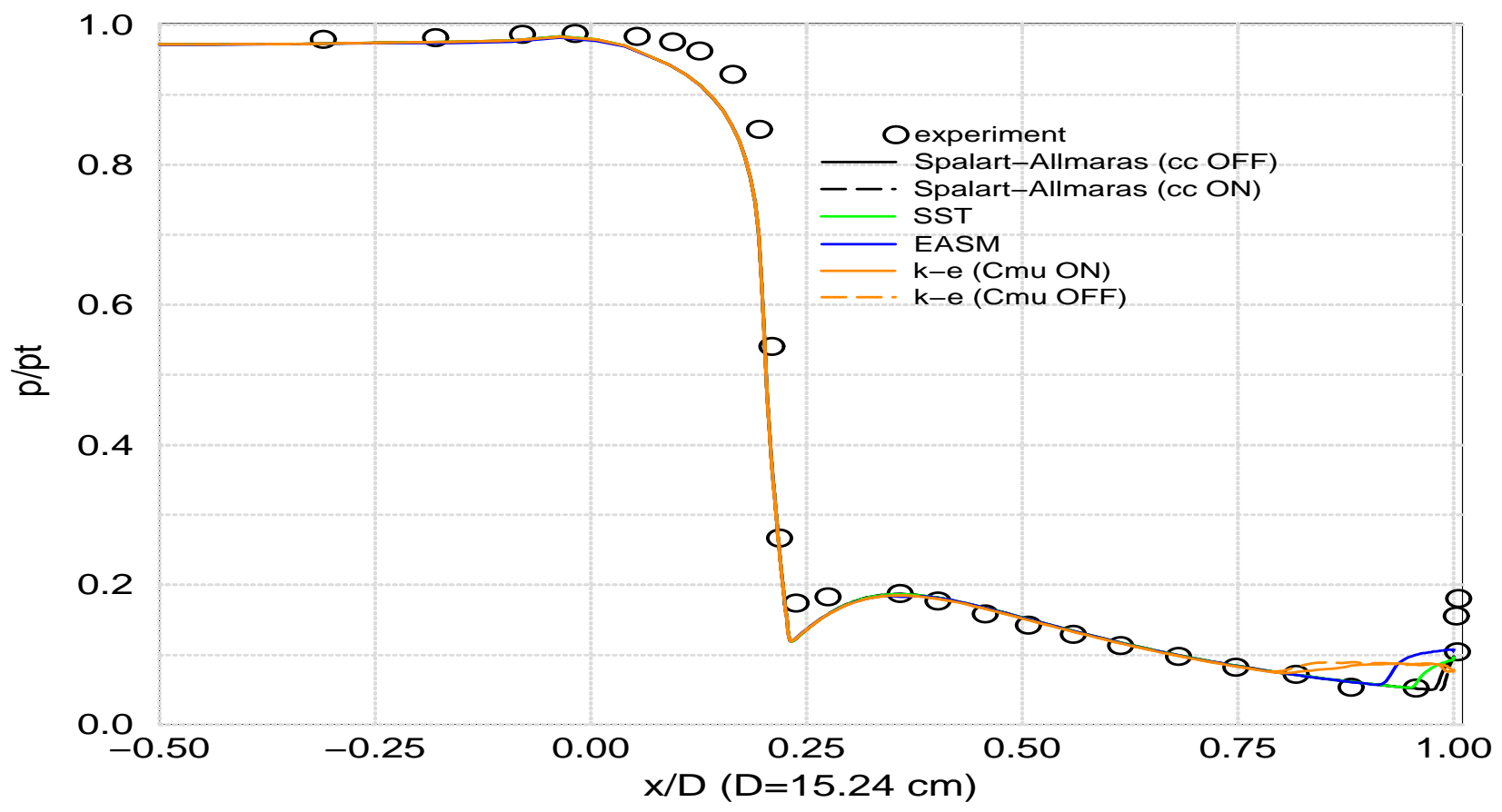

Figure 16(b): Mean $p / p_{t}$ profiles on the internal nozzle surface at an NPR of 4 and Mach number of 1.2. 


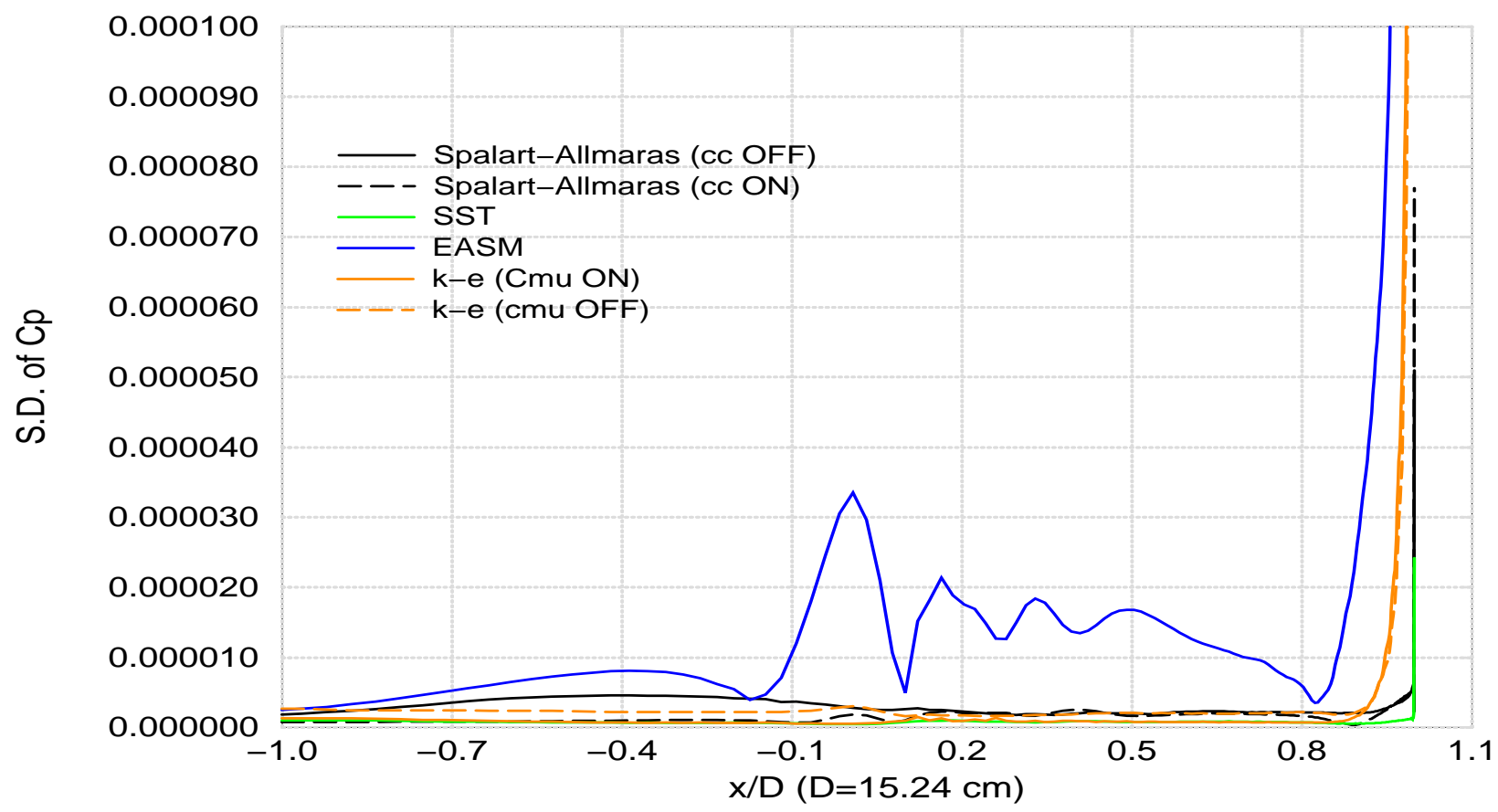

Figure 17(a): Standard Deviation curves of $\mathrm{Cp}$ on the external surface for all turbulence models at Mach 1.2, NPR=4.

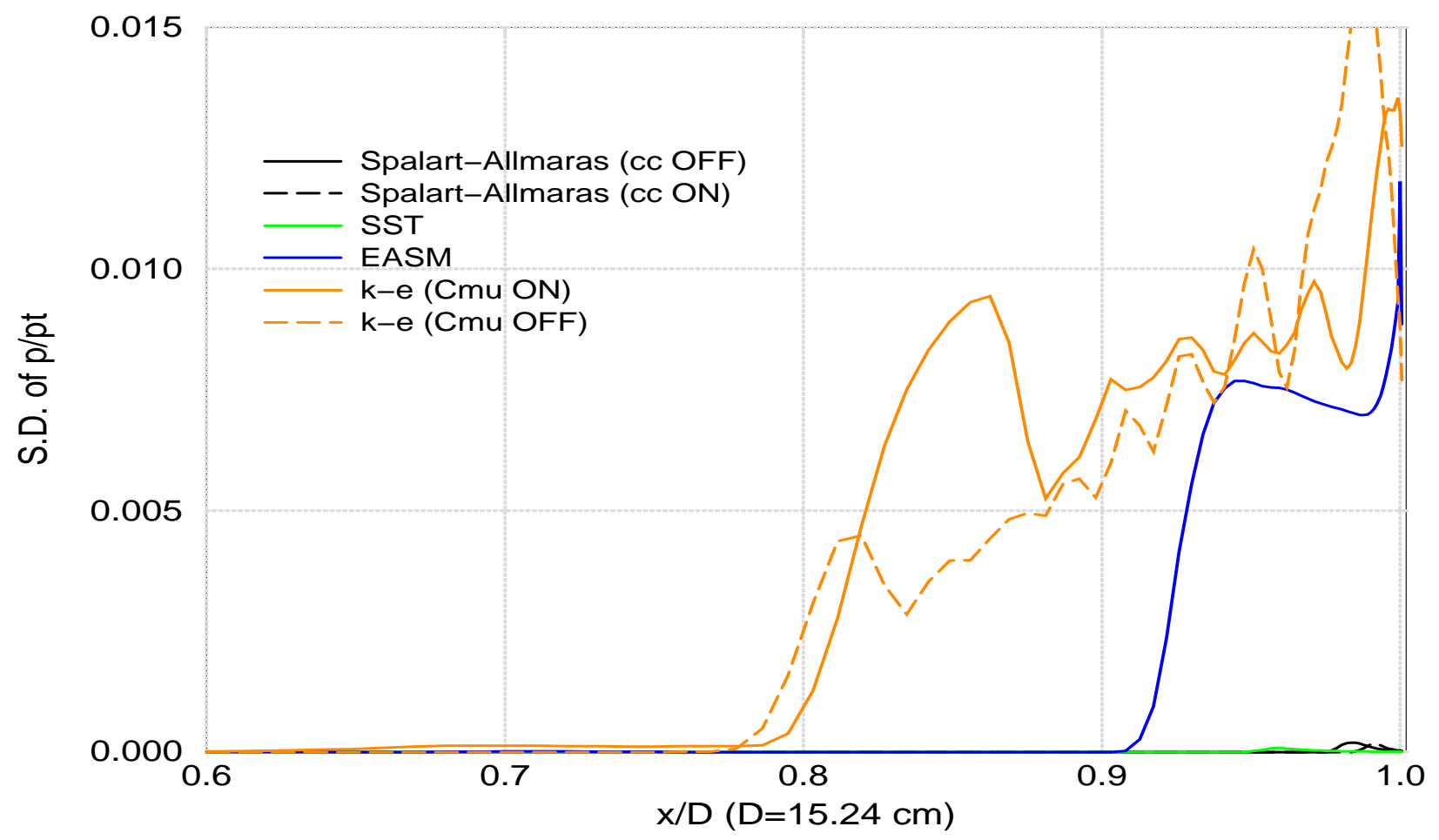

Figure 17(b): Standard Deviation curves of $\mathrm{p} / \mathrm{p}_{\mathrm{t}}$ on the internal surface for all turbulence models at Mach 1.2, $\mathrm{NPR}=4$. 
Public reporting burden for this collection of information is estimated to average 1 hour per response, including the time for reviewing instructions, searching existing data sources, gathering and maintaining the data needed, and completing and reviewing the collection of information. Send comments regarding this burden estimate or any other aspect of this collection of information, including suggestions for reducing this burden, to Washington Headquarters Services, Directorate for Information Operations and Reports, 1215 Jefferson Davis Highway, Suite 1204, Arlington, VA 22202-4302, and to the Office of Management and Budget, Paperwork Reduction Project (0704-0188), Washington, DC 20503.

\begin{tabular}{|l|l|l|}
\hline 1. AGENCY USE ONLY (Leave blank) & $\begin{array}{c}\text { 2. REPORT DATE } \\
\text { December } 2003\end{array}$ & $\begin{array}{r}\text { 3. REPORT TYPE AND DATES COVERED } \\
\text { Technical Memorandum }\end{array}$
\end{tabular}

4. TITLE AND SUBTITLE 5. FUNDING NUMBERS

Computational Study of Axisymmetric Off-Design Nozzle Flows

6. $\operatorname{AUTHOR(S)}$

WBS-22-708-73-22

Teryn DalBello, Nicholas Georgiadis, Dennis Yoder, and Theo Keith

7. PERFORMING ORGANIZATION NAME(S) AND ADDRESS(ES)

National Aeronautics and Space Administration

John H. Glenn Research Center at Lewis Field

Cleveland, Ohio 44135-3191

8. PERFORMING ORGANIZATION REPORT NUMBER

E-14289

9. SPONSORING/MONITORING AGENCY NAME(S) AND ADDRESS(ES)

National Aeronautics and Space Administration

Washington, DC 20546-0001

10. SPONSORING/MONITORING AGENCY REPORT NUMBER

NASA TM-2003-212876

AIAA-2004-0530

\section{SUPPLEMENTARY NOTES}

Prepared for the 42nd Aerospace Sciences Meeting and Exhibit sponsored by the American Institute of Aeronautics and Astronautics, Reno, Nevada, January 5-8, 2004. Teryn DalBello and Theo Keith, University of Toledo, Toledo, Ohio 43606; and Nicholas Georgiadis and Dennis Yoder, NASA Glenn Research Center. Responsible person, Teryn DalBello, organization code 5860, 216-433-8412.

12a. DISTRIBUTION/AVAILABILITY STATEMENT 12b. DISTRIBUTION CODE

Unclassified - Unlimited

Subject Categories: 02 and 34

Distribution: Nonstandard

Available electronically at http://gltrs.grc.nasa.gov

This publication is available from the NASA Center for AeroSpace Information, 301-621-0390.

13. ABSTRACT (Maximum 200 words)

Computational Fluid Dynamics (CFD) analyses of axisymmetric circular-arc boattail nozzles operating off-design at transonic Mach numbers have been completed. These computations span the very difficult transonic flight regime with shock-induced separations and strong adverse pressure gradients. External afterbody and internal nozzle pressure distributions computed with the Wind code are compared with experimental data. A range of turbulence models were examined, including the Explicit Algebraic Stress model. Computations have been completed at freestream Mach numbers of 0.9 and 1.2, and nozzle pressure ratios (NPR) of 4 and 6. Calculations completed with variable time-stepping (steady-state) did not converge to a true steady-state solution. Calculations obtained using constant timestepping (timeaccurate) indicate less variations in flow properties compared with steady-state solutions. This failure to converge to a steady-state solution was the result of using variable time-stepping with large-scale separations present in the flow. Nevertheless, time-averaged boattail surface pressure coefficient and internal nozzle pressures show reasonable agreement with experimental data. The SST turbulence model demonstrates the best overall agreement with experimental data.

14. SUBJECT TERMS 15. NUMBER OF PAGES

Transonic; Separation; Boattail; Nozzle; Turbulence; Convergent-divergent; Wind; Axisymmetric; Afterbody

\begin{tabular}{|c|c|c|}
\hline $\begin{array}{c}\text { 17. SECURITY CLASSIFICATION } \\
\text { OF REPORT } \\
\text { Unclassified }\end{array}$ & $\begin{array}{c}\text { 18. SECURITY CLASSIFICATION } \\
\text { OF THIS PAGE } \\
\text { Unclassified }\end{array}$ & $\begin{array}{c}\text { 19. SECURITY CLASSIFICATION } \\
\text { OF ABSTRACT } \\
\text { Unclassified }\end{array}$ \\
\hline
\end{tabular}

